\title{
DLX-2, MASH-1, and MAP-2 Expression and Bromodeoxyuridine Incorporation Define Molecularly Distinct Cell Populations in the Embryonic Mouse Forebrain
}

\author{
Matthew H. Porteus, ${ }^{1,2}$ Alessandro Bulfone, ${ }^{1}$ Jen-Kuei Liu, ${ }^{1}$ Luis Puelles, ${ }^{3}$ Li-Ching Lo, ${ }^{4}$ and John L. R. \\ Rubenstein' \\ 'Nina Ireland Laboratory of Developmental Biology, Center for Neurobiology and Psychiatry, Department of Psychiatry, \\ Program in Neuroscience and Developmental Biology, University of California, San Francisco, California 94143-0984, \\ ${ }^{2}$ Nancy Pritzker Laboratory, Department of Psychiatry, Stanford Medical School, Stanford, California 94305, ${ }^{3}$ Department \\ of Morphology, Faculty of Medicine, University of Murcia, Spain 30100, and ${ }^{4}$ Howard Hughes Medical Institute, Division of \\ Biology 216-76, California Institute of Technology, Pasadena, California 91106
}

Recently, the $D I x$ family of homeobox genes have been identified as candidates for regulating patterning and differentiation of the forebrain. We have made a polyclonal antiserum to the protein product of the DIx-2 gene. Using this antiserum, we have characterized the spatial and temporal pattern of DLX-2 protein expression during murine development and in the adult mouse brain. These studies demonstrate that, like the mRNA from the DIX-2 gene, DLX-2 protein is expressed in mouse embryonic forebrain, limbs, tail, genital tubercle, and branchial arches. Within the embryonic forebrain, DLX-2 protein is expressed within specific transverse and longitudinal domains. Analysis of expression within the wall of the forebrain shows that DLX-2 is eXpressed in proliferative regions including the ventricular and subventricular zones. DLX-2 is expressed in the same cells as MASH-1, a marker of relatively undifferentiated cells, but in a reciprocal fashion to MAP-2, a marker of terminal neuronal differentiation. A number of DLX-2-expressing cells, but not all, can be labeled with bromodeoxyuridine (BrdU). Using the patterns of DLX-2, MASH-1, MAP-2 expression, and bromodeoxyuridine incorporation, we identify four molecularly distinct populations of cells that may correspond to different stages of neuronal differentiation in the mouse basal forebrain, in which DLX-2 is expressed at the transition from proliferation to terminal differentiation.

[Key words: DLX-2, MASH-1, MAP-2, bromodeoxyuridine, antibody, homeobox, forebrain, development, differentiation]

\footnotetext{
Received Feb. 15, 1994; revised Apr. 15, 1994; accepted Apr. 27, 1994.

We thank Sue McConnell, David Anderson, and Roland Ciaranello for their constructive reading of the manuscript and helpful suggestions. We thank David Morilak and Steve Garlow for their advice and suggestions throughout this work. M.H.P. was supported by the Merck Corporation as part of the Stanford Medical Scientist Training Program. Support for this work comes from grants to J.L.R.R. from the Pfizer Scholars, John Merck Scholars, NARSAD Young Investigator, and Basil O'Connor-March of Dimes programs, and the NIMH (RO1 MH4942801, KO2 MH01046-01)

Correspondence should be addressed to John L. R. Rubenstein, Nina Ireland Laboratory of Developmental Biology, Center for Neurobiology and Psychiatry, Department of Psychiatry and Programs in Neuroscience and Development, 401 Parnassus Avenue, UCSF, San Francisco, CA 94143-0984.

Copyright (C) 1994 Society for Neuroscience $0270-6474 / 94 / 146370-14 \$ 05.00 / 0$
}

The mammalian forebrain develops from the prosencephalon at the rostral end of the neural tube and consists of structures such as the cerebral cortex, basal ganglia, hippocampus, hypothalamus, and thalamus. Despite the complexity of its functioning, recent studies have shown that the mammalian forebrain shares developmental strategies with simpler systems. In particular, genes from the homeobox, basic helix-loop-helix, Wnt, growth factor, and steroid receptor gene families have been found to have specific spatial and temporal expression patterns in the forebrain (reviewed in Puelles and Rubenstein, 1993; Rubenstein and Puelles, in press). These gene families have proven roles in regulating pattern formation and cell differentiation in both invertebrates and vertebrates (Lawrence, 1992; McGinnis and Krumlauf, 1992).

The mammalian hindbrain, like the invertebrate embryo, may have a segmental blueprint (Lumsden and Keynes, 1989; Keynes and Lumsden, 1990). In the hindbrain, the segments are called rhombomeres. Rhombomere identity in the hindbrain is thought to be determined in part by the expression of the Hox family of genes (reviewed in Krumlauf et al., 1993). On a morphologic basis, the forebrain has a less clear segmental organization. The expression patterns of putative regulatory genes recognize boundaries that are consistent with a segmental organization of the forebrain (Bulfone et al., 1993a; Puelles and Rubenstein, 1993). In the forebrain, the repeating segments are called prosomeres. We have hypothesized that the identity of the prosomeres is codified by master regulatory genes, including the $D l x$ genes. In addition, Figdor and Stern (1993) have shown that the prosomemeric boundaries in the diencephalon may correspond to borders of cell migration and thus are like the segmental borders in the Drosophila embryo (Lawrence, 1992) and mammalian hindbrain (Fraser et al., 1990), which are boundaries that restrict cell migration and cell lineage.

To understand patterning and differentiation in the mouse forebrain, we previously isolated a collection of genes that are preferentially expressed in the developing forebrain (Porteus et al., 1992). From this collection of about 500 different genes, we have identified several, including Tes-1, that are expressed both in regionally and temporally restricted patterns in the embryonic forebrain (Porteus et al., 1991, 1992). Tes- 1 has since been renamed $D l x-2$, as it belongs to a family of vertebrate homeobox genes (Porteus et al., 1991; Price et al., 1991; Robinson et al., 
1991; Beauchemin and Savard, 1992; Ekker et al., 1992; Papalopulu and Kintner, 1993) that are homologous within the homeobox to the Drosophila melanogaster gene distal-less $(\mathrm{Dll})$ (Cohen et al., 1989). Previously, using in situ RNA hybridization, we and others showed that $D l x-2$ has sharp borders of expression in the cmbryonic forebrain (Porteus et al., 1991; Robinson et al., 1991; Bulfone et al., 1993a,b). Moreover, the expression pattern of $D l x-2$ has some remarkable similarities to the expression of distal-less in Drosophila, suggesting that these genes have conserved both structural and expression information through evolution (Bulfone et al., 1993b).

In addition to understanding pattern formation, we also wanted to use our collection of genes to study differentiation in the forebrain. In this report, we use polyclonal antiserum against the DLX-2 protein to define the characteristics of the cells that express DLX-2 protein. In particular, we use the polyclonal antiserum to compare the expression of DLX-2 at a cellular level with the expression of MASH-1, a protein marker of a relatively undifferentiated neuronal state (Guillemot et al., 1993), MAP-2, a protein marker of terminal neuronal differentiation (Garner et al., 1988), and with the incorporation of bromodeoxyuridine (BrdU) into mitotically active cells during $\mathrm{S}$-phase. Based upon this analysis, we identify four molecularly distinct populations of cells in the embryonic forebrain and outline a sequence of stages involving transitory DLX-2 expression during early differentiation in the embryonic forebrain.

\section{Materials and Methods}

Generation of $D L X-2$ polyclonal antiserum. Using standard molecular biology techniques (Sambrook et al., 1989), $D l x-2$ cDNA was digested with HindIII/BamHI, releasing an $800 \mathrm{bp}$ fragment encoding the C-terminal 199 amino acids of DLX-2. The fragment was subcloned into the BamHI site of pET1 1d (Novagen), creating pM548. We transformed BL21DE3pLysS Escherichia coli with pM548 to create strain M565. Recombinant DLX-2 protein was generated by inoculating at a 1:100 dilution of an overnight culture of M565 in LB medium containing ampicillin $(50 \mu \mathrm{g} / \mathrm{ml})$ and chloramphenicol $(50 \mu \mathrm{g} / \mathrm{ml})$ and incubating at $37^{\circ} \mathrm{C}$ for $2-3 \mathrm{hr}$. Induction of recombinant DLX-2 was performed by adding $1 \mathrm{~mm}$ isopropyl- $\beta$-thiolgalactopyranoside (IPTG; Sigma), incubating for $30 \mathrm{~min}$, and then adding Rifampin $(200 \mu \mathrm{g} / \mathrm{ml})$. The culture was allowed to grow for $2 \mathrm{hr}$. The bacterial cells were pelleted by centrifugation, resuspended in lysis buffer (PBS/1\% Triton X-100), and then sonicated on ice. Recombinant DLX-2 was purified by polyacrylamide gel electrophoresis (SDS-PAGE). The gel region containing recombinant DLX-2 was excised, soaked in $0.1 \%$ SDS, $50 \mathrm{~mm}$ Tris $\mathrm{Cl}$

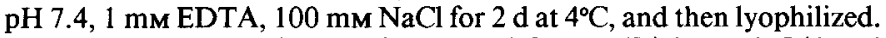
The lyophilized material was given to BabCo Inc. (Richmond, CA) and injected into two rabbits according to their standard protocol.

Generation of $D L X-2$ affinity columns for purification of antiserum. Affinity columns were made by mixing purified DLX-2 protein with AffiGel 10 matrix (Bio-Kad) according to manufacturer's specifications. Briefly, the affinity column was made by expressing the carboxyl-terminal 199 amino acid DLX-2 polypeptide in bacteria as described above. The DLX-2 polypeptide was purified by lysing bacteria in binding buffer $(6 \mathrm{M}$ urea, $5 \mathrm{~mm}$ imidazole, $500 \mathrm{~mm} \mathrm{NaCl}, 20 \mathrm{~mm}$ Tris $\mathrm{Cl}$ $\mathrm{pH}$ 7.9) followed by sonication. The lysate was then loaded onto a Nickel-charged column from Novagen, made and equilibrated according to manufacturer's specifications. The bacterial lysate was adsorbed to the nickel-charged column and the eluate was discarded. DLX-2 polypeptide bound specifically to the nickel-charged column on the basis of the eight consecutive histidine residues in the carboxyl-terminal portion of the polypeptide. The adsorbed column was washed with 10 column volumes $(15 \mathrm{ml})$ of wash buffer $(6 \mathrm{M}$ urea, $60 \mathrm{~mm}$ imidazole, $500 \mathrm{~mm} \mathrm{NaCl}, 20 \mathrm{~mm}$ Tris $\mathrm{Cl} \mathrm{pH} 7.9$ ). The DLX-2 polypeptide was eluted with 10 column volumes $(15 \mathrm{ml})$ of strip buffer $(6 \mathrm{M}$ urea, 100 mM EDTA, $500 \mathrm{~mm} \mathrm{NaCl}, 20 \mathrm{~mm}$ Tris $\mathrm{Cl} \mathrm{pH} \mathrm{7.9).} \mathrm{The} \mathrm{eluate} \mathrm{was}$ dialyzed into storage buffer $(300 \mathrm{~mm} \mathrm{KCl}, 1 \mathrm{~mm}$ EDTA, $50 \mathrm{~mm}$ HEPES $\mathrm{pH} 7.6$ ) and stored at $-70^{\circ} \mathrm{C}$. Purified DLX-2 was mixed with $1 \mathrm{ml}$ of
Affigel- 10 for $4 \mathrm{hr}$ at $4^{\circ} \mathrm{C}$, resulting in the covalent attachment of DLX-2 polypeptide to the Affigel-10 matrix. The matrix was washed with 20 $\mathrm{ml}$ of PBS and stored under PBS containing $0.2 \%$ sodium azide at $4^{\circ} \mathrm{C}$. We call this column the Georg column.

The C-terminal 124 amino acids of DLX-2 was subcloned into pGEX$2 \mathrm{~T}$ (Promega), a bacterial expression vector creating glutathione- $S$ transferase-DLX-2 fusion protein. This expression construct is called pM659. The GST-DLX-2 fusion protein was purified as above using a nickel-charged column and used to create an Affigel-10-coupled column as described above. This column is called the Hackl column. In summary, the Georg column contains the carboxyl-terminal 199 amino acids (C-199) of DLX-2, while the Hackl column contains the carboxyl-terminal 124 amino acids (C-124) of DLX-2 as a fusion protein with glutathione- $S$-transferase.

Affinity purification of $D L X-2$ antiserum. Antiserum $(10 \mathrm{ml})$ from rabbit 2 was extracted by making $50 \%$ saturated with ammonium sulfate and incubating at $4^{\circ} \mathrm{C}$ for $60 \mathrm{~min}$ followed by centrifugation for $10 \mathrm{~min}$ at $2000 \times \mathrm{g}$. The pellet was resuspended in $20 \mathrm{ml}$ of PBS $(130 \mathrm{~mm}$ $\mathrm{NaCl}, 7 \mathrm{mM} \mathrm{Na}_{2} \mathrm{HPO}_{4}, 3 \mathrm{~mm} \mathrm{NaHPO}$ ) and stored at $-70^{\circ} \mathrm{C}$. Aliquots of the resuspended sera were affinity purified by passing three times at $4^{\circ} \mathrm{C}$ over either the Georg or Hackl affinity columns. Anti-C199 was purified using the Georg column, while anti-C124 was purified using the Hackl column. After passing the same serum aliquot over the column three times, the column was washed with 10 column volumes $(10 \mathrm{ml})$ of $1 \mathrm{M} \mathrm{NaCl}$ at room temperature. Enriched anti-DLX-2 antiserum was eluted by washing the column with 10 column volumes of $0.2 \mathrm{M}$ glycine $\mathrm{HCl}(\mathrm{pH} 2.2)$ at $4^{\circ} \mathrm{C}$. The column was restored by washing with copious amounts of PBS ( $>50 \mathrm{ml}$ ) until the flow-through had a $\mathrm{pH}$ of 7.4. The eluate was neutralized to $\mathrm{pH} 7.0$ with unbuffered $1 \mathrm{~m}$ Tris. The Trisglycine solution, containing enriched anti-DLX-2 antiserum, was dialyzed overnight with at least three buffer changes at $4^{\circ} \mathrm{C}$ against PBS and stored at $-70^{\circ} \mathrm{C}$.

Western analysis. A eukaryotic expression plasmid, called pM640, was made by inserting the 1.3 kilobases of $D l x-2$ cDNA from -300 relative to the initiation codon to the termination codon (Porteus et al., 1991) into pSVK3 (Promega). Expression in eukaryotic cells is driven by an SV 40 promoter and enhancer in this construct. COS cells were transfected with pM640 and pCH1 10, a plasmid that contains the $\beta$-galactosidase gene under the control of the SV40 promoter, or with pCH110 alone. Transfections were performed according to standard techniques by the DEAE-dextran method (Sambrook et al., 1989). Transfected cells were harvested $72 \mathrm{hr}$ after transfection by lysing in SDS-load buffer (10\% glycerol, $5 \% \beta$-mercaptoethanol, $2.3 \%$ SDS, $67 \mathrm{~mm}$ Tris $\mathrm{Cl} \mathrm{pH}$ 6.8 ) and stored at $-70^{\circ} \mathrm{C}$. COS cells transfected with both pM640 and pCH 110 are called $\mathrm{COS}(+)$ cells and cells transfected with only pCH110 are called $\operatorname{COS}(-)$ cells. Analysis of $\beta$-galactosidase expression was performed by layering substrate in molten agarose ( $1 \%$ agarose, PBS, $2 \mathrm{~mm}$ $\mathrm{MgCl}_{2}, 2 \mathrm{mg} / \mathrm{ml} \mathrm{X}$-gal) over paraformaldehyde-fixed and transfected cells. This procedure showed that the percentage of cells transfected in the $\operatorname{COS}(-)$ and $\operatorname{COS}(+)$ cells was equal (data not shown).

Tissue extracts from E14.5 mouse embryos were made from freshly dissected mouse forebrain, spinal cord, and liver in PBS at $4^{\circ} \mathrm{C}$. Dissected tissue was then placed in extract buffer $(10 \%$ glycerol, $5 \% \beta$-mer-

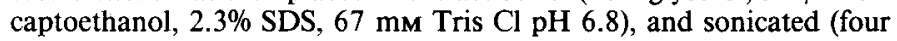
times for $30 \mathrm{sec}$ each) at $4^{\circ} \mathrm{C}$, and stored at $-70^{\circ} \mathrm{C}$.

Western analysis was performed essentially according to standard techniques (Sambrook et al.,1989). In brief, tissue extract from either transfected COS cells, purified bacterially expressed protein, or E14.5 tissue was heated to $95^{\circ} \mathrm{C}$ for $5 \mathrm{~min}$, loaded onto a $12.5 \%$ polyacrylamide denaturing gel, and separated by electrophoresis. After electrophoresis, the protein was transferred to $0.2 \mu \mathrm{M}$ nitrocellulose (Bio-Rad) by electrophoretic transfer overnight at $4^{\circ} \mathrm{C}$ at $35 \mathrm{~mA}$. Staining was performed by first blocking in PBST (PBS with 0.2\% Tween-20) with $4 \%$ dried milk for 30 min followed by incubation with anti-DLX-2 antiserum in PBS at 1:100 dilution for $60 \mathrm{~min}$. The filter was then washed three times for $10 \mathrm{~min}$ in PBST containing 4\% dried milk. Secondary alkaline phosphatase-conjugated goat anti-rabbit antibody (Pharmacia) was added in PBST at a concentration of 1:10,000 and incubated for $60 \mathrm{~min}$ at room temperature. The filter was then washed three times for $10 \mathrm{~min}$ in TBST (10 mm Tris $\mathrm{Cl} \mathrm{pH} \mathrm{7.4,} 150 \mathrm{~mm} \mathrm{NaCl}, 02 \%$ Tween-20). Color development was performed by incubating the filter in the dark in 100 mм Tris $\mathrm{Cl} \mathrm{pH} 9.5,100 \mathrm{~mm} \mathrm{NaCl}, 5 \mathrm{~mm} \mathrm{MgCl}_{2}$ containing nitro blue tetrazolium (NBT) and 5-bromo-4-chloro-3-indolyl-phosphate (BCIP) as alkaline phosphatase color substrates until the appropriate level of staining was obtained. The color reaction was terminated by rinsing the 
filter three times with distilled water and the filter was stored dry in the dark.

Immunohistochemistry. Sections $(10 \mu \mathrm{m})$ of mouse embryos or postnatal mouse brains were prepared by cryostat sectioning as previously described (Porteus et al., 1991). Sections were stained in the following manner. Sections were fixed with freshly prepared $4 \%$ paraformaldehyde/PBS for $60 \mathrm{~min}$ at room temperature followed by washing three times for $5 \mathrm{~min}$ in PBS. Sections were blocked by incubating with $100 \%$ sheep serum for $30 \mathrm{~min}$ at room temperature. The sheep serum was removed, and primary anti-DLX-2 antiserum was added at a dilution of $1: 50$ for anti-C199 or $1: 20$ for anti-C124 in primary buffer (PBS, $10 \%$ sheep serum, $0.05 \%$ thimerosal) and incubated overnight at $4^{\circ} \mathrm{C}$. After the overnight incubation, the sections were washed three times for 5 min with PBS at room temperature. Next, secondary biotinylated-conjugated sheep anti-rabbit antibody (1:200 in PBS/10\% sheep serum) was added and incubated at room temperature for $60 \mathrm{~min}$. The sections were washed three times for $5 \mathrm{~min}$ in PBS. Tertiary horseradish peroxidase-conjugated streptavidin (1:1000 in PBS) was added and incubated for $60 \mathrm{~min}$ at room temperature. The sections were washed three times for 5 min each in PBS. Staining was performed by incubating the sections at room temperature in color reagent solution $(0.05 \%$ diaminobenzidine, $0.006 \% \mathrm{H}_{2} \mathrm{O}_{2}$ ) until appropriate staining was obtained, usually $20-30 \mathrm{~min}$. The staining was terminated by washing in water and the sections were dehydrated through graded cthanols into xylene and then coverslipped with Permount and stored at room temperature in the dark.

MASH-1 immunohistochemistry was essentially performed as previously described (Lo et al., 1991). Briefly, after fixation and washing as described above for DLX-2 immunohistochemistry, sections were blocked with undiluted horse serum and incubated with anti-MASH-1 monoclonal antibody at a $1: 4$ dilution overnight at $4^{\circ} \mathrm{C}$ in primary buffer. Sections were then washed three times for $5 \mathrm{~min}$ at room temperature in PBS. Secondary antibody and tertiary antibodies were incubated and washed according to manufacturer's specifications for the Vectastain anti-mouse staining kit (Vector Labs). Color reaction and mounting were performed as described for DLX-2 immunohistochemistry described above.

MAP-2 immunohistochemistry was performed by fixing, washing, and blocking sections as described above for DLX-2 immunohistochemistry. Sections were incubated in primary antibody (monoclonal mouse anti-MAP-2 (Boehringer-Mannheim) diluted to 1:100 in primary buffer) overnight at $4^{\circ} \mathrm{C}$. Sections were then washed three times in PBS for $5 \mathrm{~min}$ at room temperature. Sections were then incubated in secondary antibody (goat anti-mouse horseradish peroxidase conjugated at 1:200 in PBS/ $10 \%$ sheep sera) for $60 \mathrm{~min}$ at room temperature. Washing, color reaction, and mounting were then performed as described above for DLX-2 immunohistochemistry.

Double immunofluorescence was performed by fixing and washing the sections as described above and then incubating in primary solution (anti-C124 at 1:20, anti-MASH- 1 at 1:4, 10\% sheep serum, $0.05 \%$ thimerosal, PBS) overnight at $4^{\circ} \mathrm{C}$. Sections were washed three times for $5 \mathrm{~min}$ at room temperature in PBS. Sections were then incubated in secondary solution (PBS, 10\% sheep sera, 1:100 fluorescein-conjugated anti-mouse IgG, 1:10 rhodamine-conjugated anti-rabbit IgG) for $60 \mathrm{~min}$ at room temperature in the dark. Sections were then washed in PBS four times for 5 min each at room temperature in the dark, with the last wash containing $10 \mu \mathrm{g} / \mathrm{ml} \mathrm{4}^{\prime}, 6$-diamidino-2'-phenylindole (DAPI). Slides were coverslipped with Glycergel mounting solution and stored at $-70^{\circ} \mathrm{C}$ in the dark. Using this technique, MASH-1 protein is labeled with a fluorescein-conjugated antibody, DLX-2 protein is labeled with a rhodamine-conjugated antibody, and cell nuclei are stained with DAPI. Photography was performed using a Nikon Optiphot-2 microscope with appropriate filters in the dark.

Bromodeoxyuridine pulse labeling and detection. Pregnant mice at E12.5 were injected intraperitoneally with $100 \mu \mathrm{g} / \mathrm{gm}$ body weight of 5 -bromo-2'-deoxyuridine (BrdU) in $0.9 \% \mathrm{NaCl}$. The injected mice were sacrificed $60 \mathrm{~min}$ after injection and the embryos were harvested, stored, and sectioned as previously described (Porteus et al., 1991).

BrdU staining was performed as follows. The sections were fixed in 4\% paraformaldehyde/PBS for $30 \mathrm{~min}$ at room temperature. The sections were then denatured in $2 \mathrm{~N} \mathrm{HCl}$ for $1 \mathrm{hr}$ at room temperature and then neutralized by washing at least six times in PBS for 5 min each at room temperature. The sections were stained using mouse monoclonal anti-BrdU antibody (Becton-Dickinson) at 1:100 and the anti-mouse Vectastain detection kit from Vector labs (Burlingame, CA) as described above for MASH-1 immunohistochemistry. Mouse monoclonal antiBrdU antibody was obtained from Becton-Dickinson and used at a concentration of $1: 100$.

Image analysis. Images for Figures 2, 3, 4, 5, 6, 7, 9, and 10 were captured and processed using a Nikon Optiphot-2 microscope and IMAGE 1.52 software and PERSUASION 2.1 software. Figure 1 was created by capturing and processing the image with a Nikon $35 \mathrm{~mm}$ camera and IMAGE 1.52 and PERSUASION software. Figure 8 was made by photographing through a Nikon Optiphot-2 microscope using appropriate filters to capture fluorescein and rhodamine fluorescence using Kodachrome 400 film.

\section{Results}

\section{Production and characterization of $D L X-2$ antiserum}

We expressed the carboxyl-terminal 199 amino acids of the $D l x-2$ gene in bacteria. The deduced polypeptide contains a stretch of eight consecutive histidines and the homeobox, predictions that we tested in two ways. The recombinant protein bound to nickel-linked affinity columns, consistent with the presence of the polyhistidine domain (data not shown). Likewise, gel shift experiments showed that the recombinant protein specifically bound to an oligonucleotide encoding a consensus homeobox binding sequence but not to nonconsensus sequences (Porteus, Liu, and Rubenstein, unpublished observations).

Recombinant DLX-2 protein was purified and injected into rabbits. The resulting serum was purified using either a column linked to the carboxyl-terminal 199 amino acids, which includes the homeodomain, or a column linked to the carboxyl-terminal 124 amino acids, which contains only the carboxyl-terminal eight amino acids of the homeodomain but no other sequences with significant homology to proteins currently in the GenBank/ EMBL databases. In addition, outside the homeodomain, there is no significant homology between DLX-1, a second murine member of the DLX family of homeobox genes, and DLX-2 (Price et al., 1991; data not shown). Thus, antiserum purified against the second column would not be expected to cross-react with DLX-1. Antiserum purified with the first column is called anti-C199 and antiserum purified with the second column is called anti-C124.

We performed a series of Western analyses to test the specificity of the antisera. We found that anti-C199 bound recombinant DLX-1 with approximately 100 -fold less affinity than DLX-2 and anti-C124 bound DLX-1 with at least 1000 -fold less affinity than DLX-2 (Fig. 1). We then transfected COS cells with the full coding region of the $D l x-2$ cDNA. Figure 1 shows that anti-C124 binds to a $45 \mathrm{kDa}$ band in COS cells that have been transfected with the $D l x-2$ cDNA but not in cells that have been transfected with a control plasmid. Figure 1 shows that anti-C124 recognizes an identically sized $45 \mathrm{kDa}$ band in embryonic day 14.5 (E14.5) forebrain but not in E14.5 spinal cord or liver. Western analysis of E14.5 forebrain, spinal cord, and liver with anti-C124 shows a number of bands that are stained in all three lanes. These bands are probably nonspecific and immunohistochemical analysis of an E14.5 mouse embryo shows there is no staining above background in the spinal cord or the liver (Fig. 1). Thus, while anti-C124 is not completely specific for DLX-2, the cross-reactivity does not compromise the use of the antiserum for immunohistochemistry.

While the anti-C124 serum recognizes a $45 \mathrm{kDa}$ band, the predicted molecular weight of DLX-2 is $36 \mathrm{kDa}$. These data suggest either that DLX-2 is posttranslationally modified (e.g., phosphorylation) in both COS cells and mouse embryonic forebrain to a molecular weight of $45 \mathrm{kDa}$ or that $\mathrm{DLX}-2$ runs 


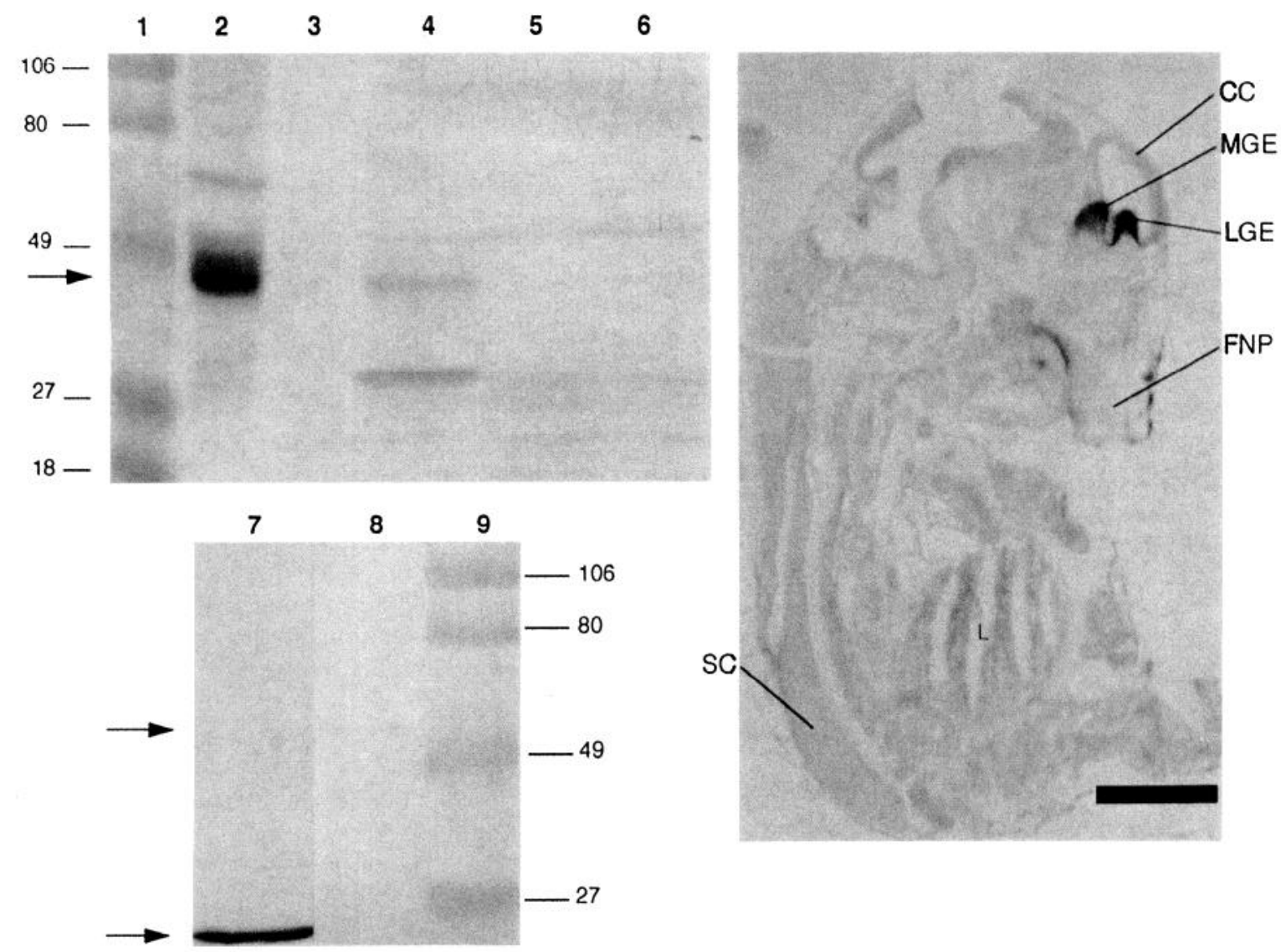

Figure 1. Specificity of DLX-2 antisera. This figure shows the specificity and cross-reactivity of the anti-DLX-2 antiserum. Lanes $1-9$ show the reactivity of anti-C124 to various protein preparations using Western analysis. Lanes $I$ and 9 are protein standards with the size of the standards in kilodaltons ( $\mathrm{kDa}$ ) shown next to them. The arrow to the left of lanes 1-5 marks the DLX-2 band that anti-C124 stains in COS cells transfected with a DLX-2-expressing plasmid (lane 2) and in E14.5 forebrain (lane 4) but not in COS cells transfected with control plasmid (lane 3) or in E14.5 spinal cord (lane 5) and liver (lane 6). Lane 7 contains a DLX-2 polypeptide (C124) purified from bacteria that was used to generate the anti-DLX-2 antiserum, while lane 8 contains a purified bacterially expressed full-length DLX-1 glutathione- $S$-transferase fusion protein (there is $\sim 100$-fold more protein in lane 8 than in lane 7). The arrows to the left of lanes 7-9 mark the $27 \mathrm{kDa}$ DLX-2 and $53 \mathrm{kDa}$ DLX-1 bands. The right panel shows immunohistochemistry performed on a parasagittal section of a mouse E14.5 embryo. In this section, there is no labeling above background of the spinal cord and liver while there is strong labeling of the medial ganglionic eminence $(M G E)$, lateral ganglionic eminence ( $L G E)$, and the ectodermal cells of the frontonasal prominence $(F N P)$. Thus, the faint bands seen in common in the liver, spinal cord, and forebrain do not interfere with specific immunohistochemical staining and probably contribute to the background staining. See Table 1 for the abbreviations used in this and all subsequent figures. Scale bar, $240 \mu \mathrm{m}$.

anomalously in our gel system, probably secondary to intrinsic protein structure. In sum, the series of Western blots demonstrate that anti-C124 recognizes DLX-2 and can be used reliably to stain tissues to determine the expression pattern of the DLX-2 protein. We observed no differences in the staining patterns generated by anti-C124 or anti-C199 on tissue sections. With both antisera we observed strong nuclear staining, suggesting that DLX-2 is localized to the nucleus. In DLX-2-expressing cells, there is often scant cytoplasm, and thus we cannot rule out that DLX-2 protein is present in the cytoplasm as well.

Using anti-C124 and anti-C199, we characterized the expression pattern of DLX-2 protein through development. The following sections show DLX-2 protein is expressed in a regionally restricted pattern in the developing forebrain, and it is expressed in the distal aspects of embryonic structures.

\section{Expression of $D L X-2$ in the forebrain}

Our analysis of DLX-2 expression spans from E10.5 to the adult. From E10.5 to E14.5, DLX-2 is expressed in two regions of the forebrain: domains I and II (Bulfone et al., 1993b). The caudal zone, domain II, extends axially from the area of the suprachiasmatic nucleus $(\mathrm{SCH})$ through the hypothalamic cell cord (HCC) and posterior entopeduncular area (PEP) into the ventral thalamus (VT), and terminates abruptly at the zona limitans (ZL), the boundary zone that separates the dorsal thalamus (DT) from the ventral thalamus. Domains I and II are separated by a strip of DLX-2-negative tissue, called the optoeminential zone, which extends from the eminentia thalami (EMT) to the optic stalk (Bulfone et al., 1993b). Here, a small gap of expression is generally found (Fig. 3), although in some planes of section domains I and II are connected by a thin strip of DLX-2expressing cells (see Fig. 2C). The rostral zone, domain II, stretches from the junction of the lateral ganglionic eminence with the cerebral cortex down through the preoptic area and terminates in the region of the optic stalk. This domain does not extend into the caudal ganglionic eminence in the caudal telencephalon. Both domains I and II are continuous from left side to right side across the midline at the lamina terminalis. 


\begin{tabular}{|c|c|}
\hline AEP & Anterior entopeduncular area \\
\hline $\mathrm{AQ}$ & Aqueduct \\
\hline $\mathrm{CC}$ & Cerebral cortex \\
\hline $\mathrm{CoC}$ & Corpus callosum \\
\hline $\mathrm{CP}$ & Cortical plate \\
\hline DT & Dorsal thalamus \\
\hline EC & Ectoderm \\
\hline EMT & Eminentia thalami \\
\hline FNP & Frontonasal prominence \\
\hline GM & Ganglionic mantle \\
\hline GSM & Ganglionic submantle \\
\hline GT & Genital tubercle \\
\hline $\mathrm{HCC}$ & Hypothalamic cell cord \\
\hline III & Third ventricle \\
\hline IV & Fourth ventricle \\
\hline IZ & Intermediate zone \\
\hline $\mathrm{L}$ & Liver \\
\hline LGE & Lateral ganglionic eminence \\
\hline LV & Lateral ventricle \\
\hline MA & Mammillary area \\
\hline MD & Mandibular division of first branchial arch \\
\hline ME & Mesenchyme \\
\hline MGE & Medial ganglionic eminence \\
\hline MX & Maxillary division of first branchial arch \\
\hline MZ & Marginal zone \\
\hline OB & Olfactory bulb \\
\hline OR & Optic recess \\
\hline POA & Anterior preoptic area \\
\hline $\mathbf{S}$ & Striatum \\
\hline SC & Spinal cord \\
\hline $\mathrm{SCH}$ & Suprachiasmatic area \\
\hline SP & Subplate \\
\hline SVZ & Subventricular zone \\
\hline $\mathrm{T}$ & Tectum \\
\hline VT & Ventral thalamus \\
\hline $\mathrm{vZ}$ & Ventricular zone \\
\hline $\mathbf{Z L}$ & Zona limitans \\
\hline
\end{tabular}

Finally, Figure 3 demonstrates that the patterns of expression in the forebrain at E12.5, E13.5, and E14.5 are essentially indistinguishable.

At E16.5, by a process of cell division within a limited space, the forebrain is beginning to fold and appears different from the forebrain from earlier ages shown in Figure 3. Prior to E16.5, DLX-2 expression has many sharp borders of expression, for instance, between the ventral and dorsal thalamus, the cerebral cortex and lateral and medial ganglionic eminence, and the anterior entopeduncular area (AEP) and eminentia thalami (EMT). Some of these borders, for example, between the ventral and dorsal thalamus and between the AEP and EMT, remain sharp at E16.5 and throughout development (Fig. 4). Other borders, such as between the lateral ganglionic eminence and cerebral cortex and between the lateral ganglionic eminence and olfactory bulb, however, are crossed by DLX-2 expression at E16.5 (Fig. 4). The expression of DLX-2 in the olfactory bulb represents an extension of domain II at this age. Figure 4 illustrates this point in an E16.5 embryo and also demonstrates that while
DLX-2 expression remains strong in the rostral expression domains, it is beginning to weaken in more caudal domains, particularly the ventral thalamus, at E16.5.

Prior to E16.5, the cerebral cortex is conspicuously negative for DLX-2 expression. At E16.5, however, DLX-2 is expressed in dispersed cells of the subventricular, intermediate, subplate, and marginal zones of the cerebral cortex; these cells are continuous with DLX-2-positive regions of the lateral ganglionic eminence and olfactory bulb (Fig. 4). In addition, many cells of the olfactory bulb express DLX-2. Whereas DLX-2 is expressed in all cells of the subventricular zone in the ganglionic eminence and olfactory bulb, it is only expressed in a fraction of the cells of the subventricular zonc of the ccrcbral cortcx. Qualitativcly, the expression pattern in the cerebral cortex is different from that in the olfactory bulb and lateral ganglionic eminence. The DLX-2-positive cells in the cerebral cortex and olfactory bulb either arise de novo, or represent cells that have migrated from other DLX-2-positive regions such as the ganglionic eminence. In either possibility, they represent an extension of expression domain II of DLX-2 into these regions.

Previous Northern analysis showed that $D l x-2 \mathrm{mRNA}$ is expressed in the adult forebrain (Porteus et al., 1991, 1992). Immunohistochemistry shows the cells in the adult brain that express DLX-2 protein. Figure 4 demonstrates that at E16.5, DLX-2 is expressed along the entire subventricular zone from the ganglionic eminence to the olfactory bulb. We observe this same pattern of expression from the ganglionic eminence to the olfactory bulb at P17 and in the adult forebrain (Fig. 5). Through development the proportion of DLX-2-expressing cells decreases but after E16.5 there is a stream of cells that begins in a region corresponding to a subventricular zone of the primordia of the caudoputamen complex that travels beneath the corpus callosum (when it is present) over the striatum, and terminates in the olfactory bulb. Figure 5 demonstrates this cell stream at P17 and in the adult.

\section{DLX-2 is expressed in the distal ectoderm of embryonic outgrowths}

$D l x-2$ was originally named Tes- 1 (telencephalon embryonic subtraction) because of its temporal regulation in the development of the telencephalon. It was renamed $D l x-2$ because it belongs to a family of vertebrate genes that share homology in the homeobox to the distal-less gene of Drosophila. The first reports describing the members of the $D l x$ family noted that the expression pattern of the mammalian and fly genes did not seem to be related (Porteus et al., 1991; Price et al., 1991). Since that time, however, we and others have found that $D l x-1$ and $D l x-2$ are expressed in structures of the mouse embryo that correspond to analogous Drosophila structures where distal-less is expressed (Cohen, 1990; Bulfone et al., 1993a). Figures 2 and 6 develop this concept further by showing DLX-2 expression in the distal ectodermal layer of a number of structures during embryogenesis including the limbs, branchial arches, tail, genital tubercle, and frontonasal prominence (nose). All of these structures bud from the core of the embryo and in each case DLX-2 expression in the ectoderm outlines the bud, with maximal expression in the most distal ectoderm.

\section{$D L X-2$ is directly expressed with $M A S H-1$ and inversely expressed with MAP-2 in the medial ganglionic eminence}

As shown in previous sections, DLX-2 expression is spatially restricted along the longitudinal and transverse axes. Likewise, 

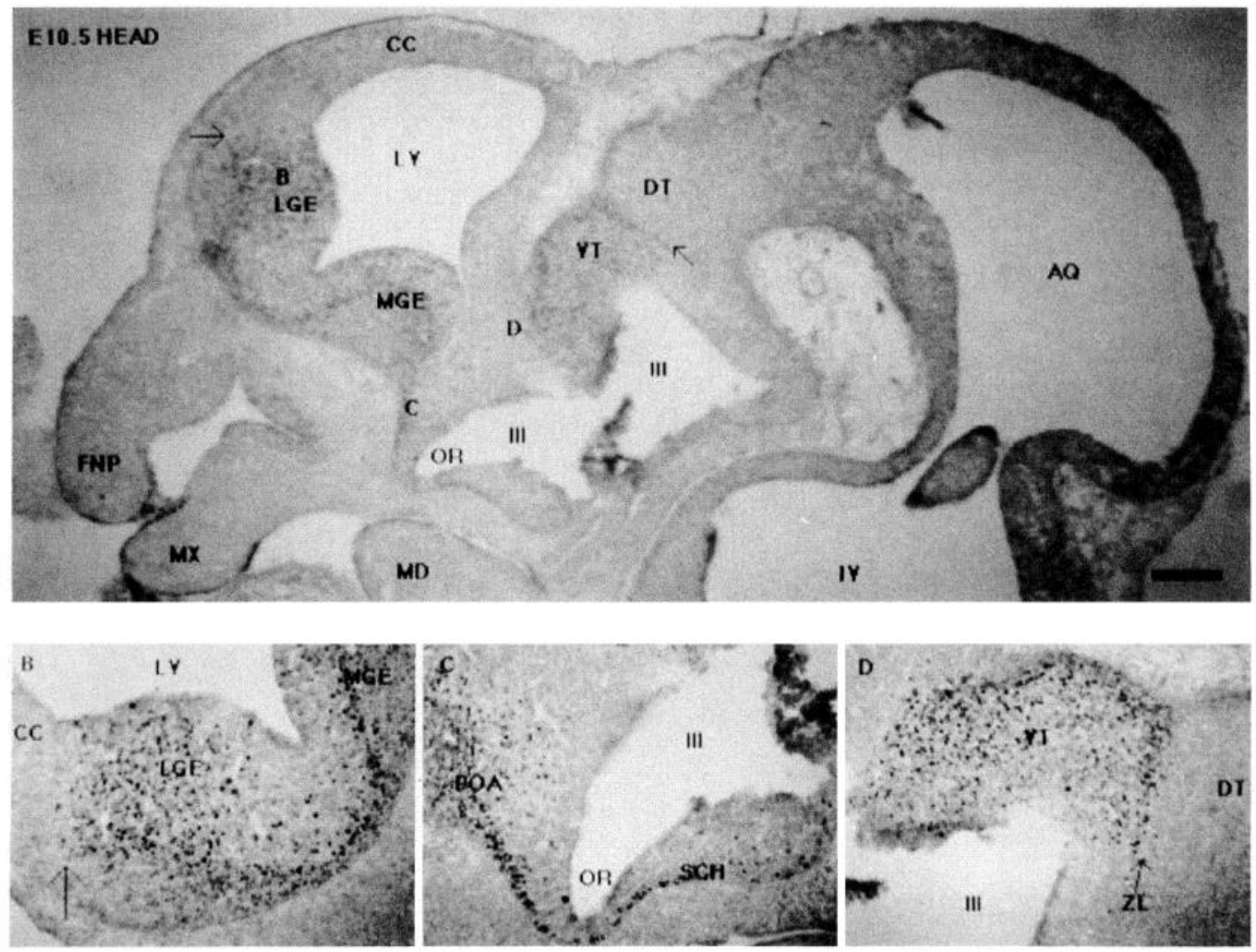

Figure 2. DLX-2 expression at E10.5. The top panel shows DLX-2 expression in a parasagittal section of a mouse E10.5 head by immunohistochemistry. The letters $B, C$, and $D$ in the top panel are regions shown at higher magnification in panels $B$, $C$, and $D$; these letters are in roughly the same relative location in the higher-magnification panels as in the lower-magnification panel. The arrows in the top panel mark borders between the lateral ganglionic eminence and cerebral cortex and between the ventral thalamus and dorsal thalamus. With reference to the lower-magnification panel, $B$ is rotated $90^{\circ}$ counterclockwise, $C$ is rotated $45^{\circ}$ counterclockwise, and $D$ is rotated $90^{\circ}$ clockwise. In $B$, the border of DLX-2 expression between the lateral ganglionic eminence and cerebral cortex is marked with an arrow. $C$ demonstrates a continuum of DLX-2 expression from domains I and II through the region of the optic stalk at E10.5. In $D$, the region of the zona limitans $(Z L)$ is marked with an arrow. The staining of the tectum and cerebellar anlage in the top panel is artifactual. Scale bar: $200 \mu \mathrm{m}$ for the top panel, $140 \mu \mathrm{m}$ for $B-D$.

it is spatially restricted along the ventricular-pial axis-a major axis of cell differentiation. An important feature of DLX-2 expression from E10.5 until E18.5 is that apparently all of the cells in the subventricular layer express DLX-2. This ubiquity of expression is deduced from visual inspection and comparison of DLX-2 expression with 4',6-diamidino-2' -phenylindole (DAPI) counterstaining on nuclei (data not shown). This result implies that as cells migrate from the ventricular zone to the mantle, they all express DLX-2 at some point in their development. To begin to define when during differentiation DLX-2 is expressed, we compared its expression with markers for different stages of neural differentiation. The three other markers we used were MASH-1, a protein expressed in the early stages of neuronal differentiation (Lo et al., 1991; Guillemot et al., 1993), MAP-2, a protein expressed in terminally differentiated neurons (Garner et al., 1988), and the incorporation of BrdU into nuclei undergoing DNA synthesis.

We compared the expression of DLX-2, MASH-1, and MAP-2 by performing immunohistochemistry on adjacent sagittal sections of tan E12.5 mouse embryo (Fig. 7). In general, our study of MASH-1 confirmed the results of Lo et al. (1991) and Guillemot and Joyner (1993). Specifically, in the CNS we found MASH-1 expression in cell nuclei of discrete domains of the spinal cord, midbrain, and forebrain. In the forebrain rostral to the zona limitans, it is expressed in an apparently identical pattern to DLX-2. Within the ganglionic eminence, MASH-1 is expressed strongest in most, if not all, cells of the subventricular zone, and weaker in scattered cells of the ventricular zone and in cells in the region covering the subventricular zone. We call this latter region the ganglionic submantle (GSM) because it lies between the mantle and the subventricular zones. DLX-2 is expressed in the same pattern in the ganglionic eminence. Using double immunofluorescence (Fig. 8), it appears that most cells within the ganglionic eminence that express one gene also express the other. In the context of the entire embryo, therefore, there are regions that express DLX-2 and MASH-1 independently. Within the E10.5-E12.5 forebrain, however, these genes are expressed in the same cells.

Consistent with previous studies (Garner et al., 1988), we found that MAP-2 is non-nuclear and expressed strongest in cells closest to the pial surface, also known as the mantle (Fig. 7). In the ganglionic eminence, it is expressed in the ganglionic mantle (GM) (Fig. 7). The ganglionic mantle is the region where cells are expected to be the most mature based on the known pattern of differentiation in the forebrain. Cells in the ganglionic submantle express MAP-2 at a lower level than in the mantle, and MAP-2 is essentially not expressed in the subventricular or ventricular zones. MAP- 2 and DLX- 2 have complementary expression patterns. In the area of highest DLX-2 expression, the subventricular zone, we see no MAP-2 expression. Conversely, 

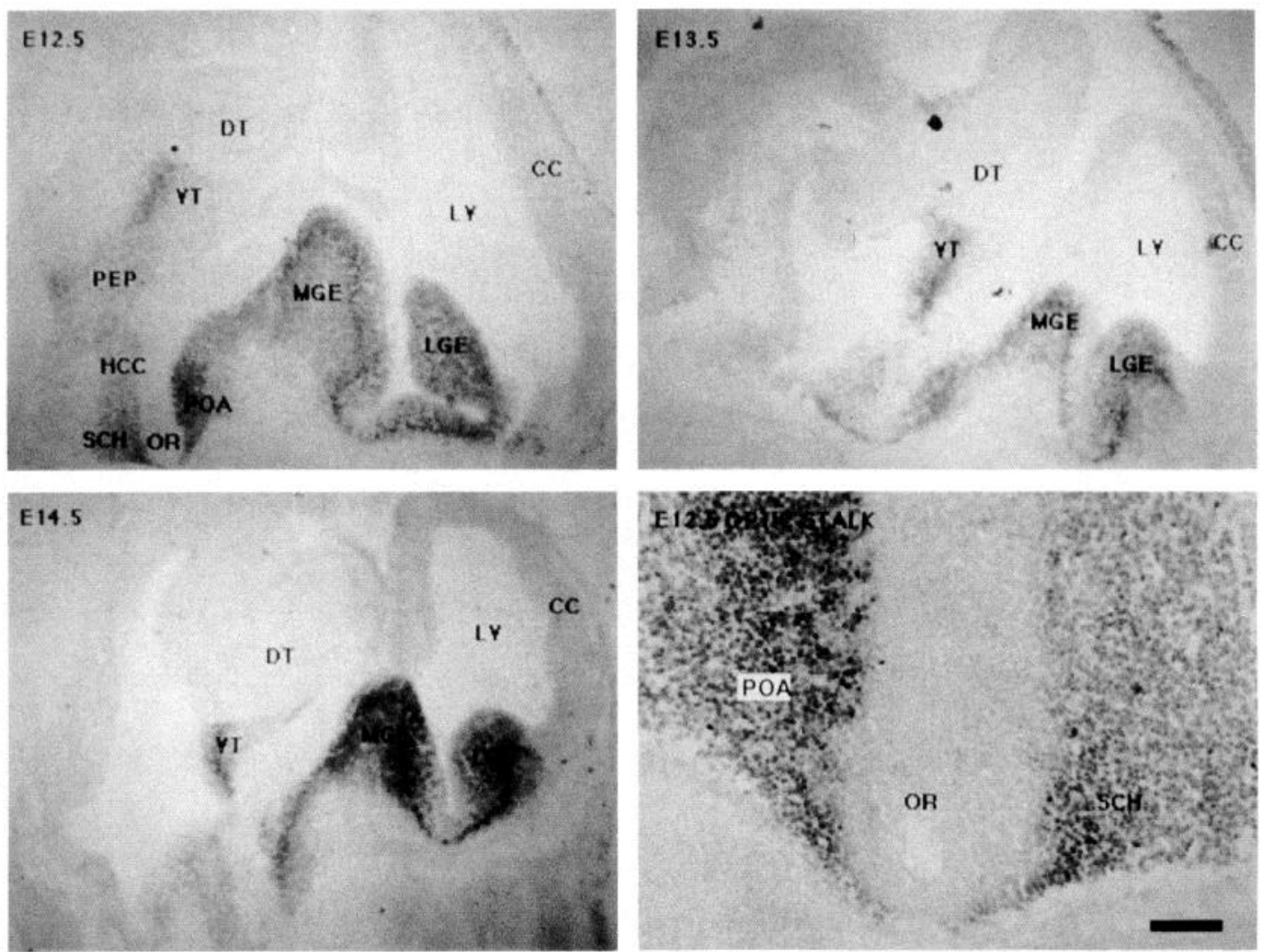

Figure 3. DLX-2 expression from E12.5-E14.5 in the forebrain. This figure shows immunohistochemical staining of DLX-2 in the forebrain of parasagittal sections from mouse E12.5, E13.5, and E14.5 embryos. The bottom right panel is a higher-magnification view of the gap between domains I and II at the optic stalk region from the E12.5 section, and is rotated $180^{\circ}$ around the vertical axis with respect to the E12.5 panel. Scale bar: $140 \mu \mathrm{m}$ for the bottom right panel, $350 \mu \mathrm{m}$ for other panels.
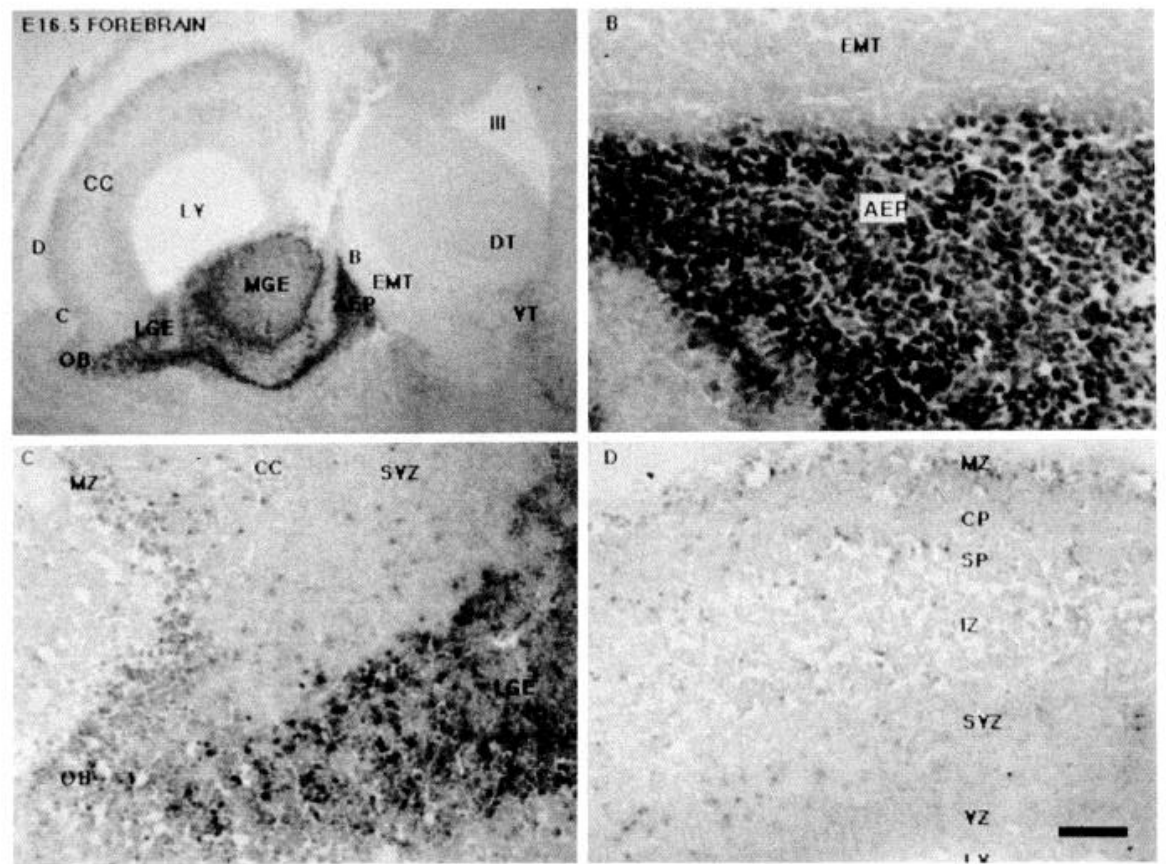

Figure 4. DLX-2 expression at E16.5 in the forebrain. This figure shows DLX-2 expression in different regions of the E16.5 mouse forebrain. The top left panel is a low-magnification view of immunohistochemical staining of DLX-2 in an E16.5 parasagittal forebrain. The letters $B$, $C$, and $D$ in the top left panel correspond to higher-magnification panels $B, C$, and $D$ and are in roughly the same relative location in the corresponding panels. With reference to the lower-magnification panel, $B$ is rotated approximately $90^{\circ}$ counterclockwise, $C$ is not rotated, and $D$ is rotated approximately $90^{\circ}$ clockwise. $B$ shows that at E16.5 the border of DLX-2 expression between the anterior entopeduncular area $(A E P)$ and eminentia thalami $(E M T)$ is maintained. $C$ shows expression of DLX-2 in cells that extend into the olfactory bulb $(O B)$, marginal zone $(M Z)$, and subventricular zone $(S V Z)$ of the cerebral cortex. $D$ shows expression of DLX-2 in scattered cells of the subventricular zone (SVZ), intermediate zone (IZ), subplate $(S P)$, cortical plate $(C P)$, and marginal $(M Z)$ zones of the cerebral cortex. In summary, this shows that DLX-2 expression at E16.5 crosses into the olfactory bulb and cerebral cortex but maintains sharp borders between the AEP and EMT and between the ventral thalamus ( $V T)$ and dorsal thalamus $(D T)$. Scale bar: $350 \mu \mathrm{m}$ for the top left panel, $70 \mu \mathrm{m}$ for the top right panel, and $140 \mu \mathrm{m}$ for the bottom two panels. 

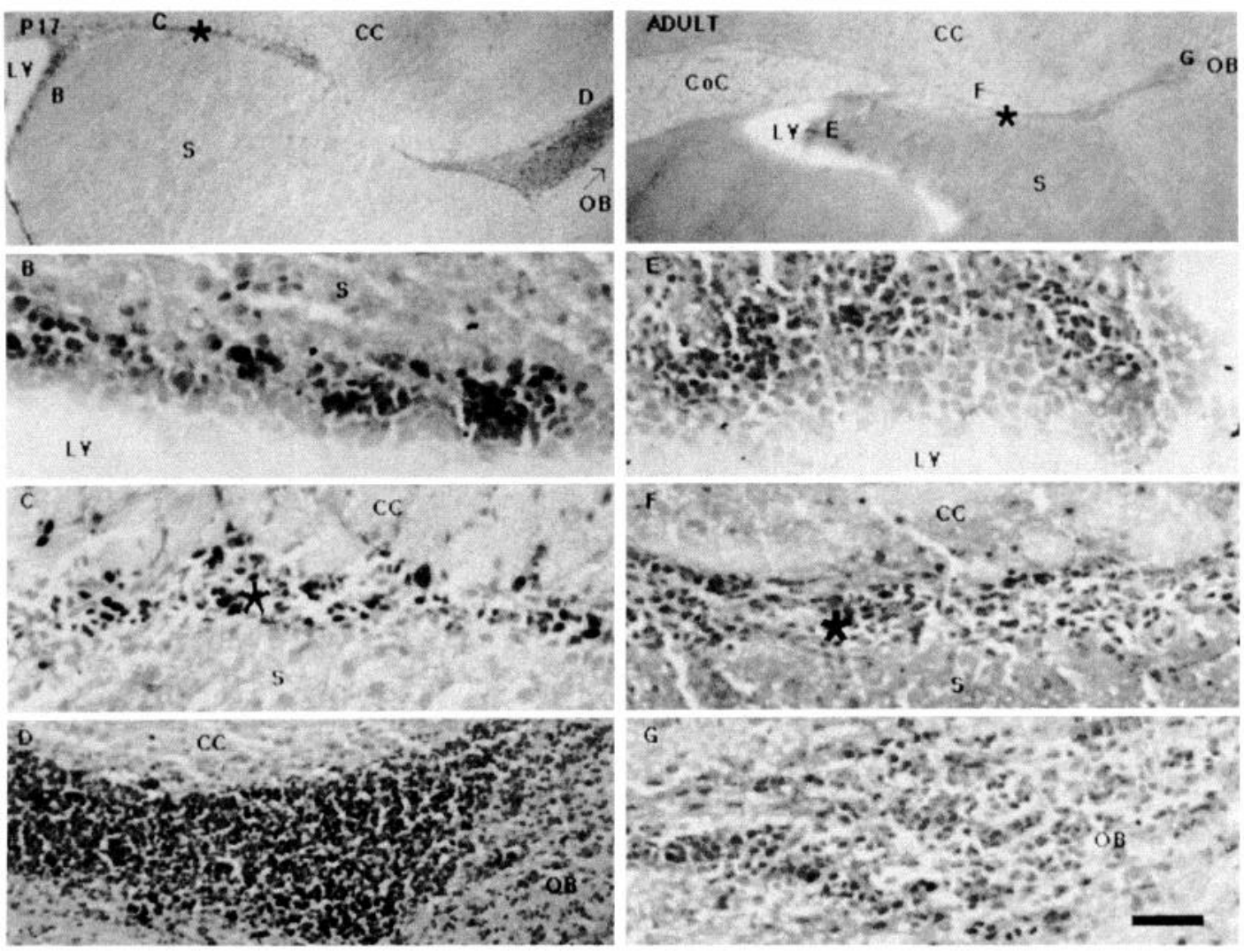

Figure 5. Expression of DLX-2 in the P17 and adult forebrain. This figure shows DLX-2 expression along the pathway from the proliferative zone of the striatum to the olfactory bulb in parasagittal sections from mouse P17 and adult brains. The top left panel shows expression at postnatal day $17(P 17)$ and the letters $B, C$, and $D$ correspond to regions shown at higher magnification in panels $B, C$, and $D$. With reference to the top left panel, $B$ is rotated approximately $90^{\circ}$ counterclockwise, while $C$ and $D$ are not rotated. $B$ shows DLX-2-positive cells in the periventricular region of the striatum. $C$ shows DLX-2-positive cells that lie between the cerebral cortex $(C C)$ and striatum $(S)$. The asterisk in the top left panel is in the same location as the asterisk in $C$. D shows DLX-2-positive cells in the olfactory bulb. The top right panel shows expression in the adult brain and the letters $E, F$, and $G$ correspond to regions shown at higher magnification in panels $E, F$, and $G$. With reference to the top right panel, $E$ is rotated approximately $90^{\circ}$ counterclockwise, while $F$ and $G$ are not rotated. $E$ shows DLX-2-positive cells in the periventricular region of the adult striatum $(S)$. F shows DLX-2-positive cells between the cerebral cortex $(C C)$ and striatum $(S)$ in the adult brain. The asterisk in the top right panel is in the same location as the asterisk in $F$. $G$ shows DLX-2-positive cells in the adult olfactory bulb $(O B)$. The letters $B, C, D, E, F$, and $G$ are in relatively the same location in the lower- and higher-magnification panels. Scale bar: $350 \mu \mathrm{m}$ for the top row, $140 \mu \mathrm{m}$ for the bottom left panel, and $70 \mu \mathrm{m}$ for all of the other panels.

in the region showing highest MAP-2 expression, the ganglionic mantle, we see no DLX-2 expresśion. In the ganglionic submantle there is both DLX-2 expression and MAP-2 expression, although at submaximal levels. Since DLX-2 expression is seen in essentially all cells of the ganglionic submantle, it is clear that there are cells that express both DLX- 2 and MAP- 2 concurrently in this zone. Identical results are found in other regions of DLX-2 expression in the forebrain, in particular, the preoptic area, the suprachiasmatic nucleus, and the ventral thalamus (Fig. 7).

\section{Is DLX-2 expressed in mitotically active cells?}

As a putative regulator of differentiation, we wished to establish whether DLX-2 was present in mitotically active cells. To test this idea, we labeled cells undergoing S-phase of the cell cycle in E12.5 mouse embryos with a pulse of 5-bromo-2'-deoxyuridine (BrdU) and compared the location of BrdU-labeled cells, with the expression of DLX-2 on adjacent sections. In the forebrain BrdU-positive cells lie in the S-phase region of the ventricular zone and in the subventricular zone (Takahashi et al., 1993). These BrdU-positive cells form a continuous layer (Fig. 9). The zone of BrdU labeling and DLX-2 labeling overlap but do not superimpose on each other (Fig. 9). Since essentially all cells in the DLX-2 layer express DLX-2 and, similarly, essentially all cells in the BrdU layer are BrdU positive, it is likely that there are cells positive for both BrdU and DLX-2 in the region where the zones overlap. Conversely, in the regions of the zones that do not overlap, there are cells that are labeled by only one marker. In the ventricular zone, we also observe discrete clusters of DLX-2-positive cells. Some of these are radially aligned, and appear as strings of single cells (Fig. 9), while others are arranged as grape-like clusters (data not shown).

\section{Discussion}

$D l x-2$ is a vertebrate homeobox gene that is among a new set of genes that have restricted spatial and temporal patterns of expression in the mammalian forebrain (Bulfone et al., 1993a; reviewed in Puelles and Rubenstein, 1993; Rubenstein and Puelles, in press). Previously, we have characterized the expression of Dlx-2 using in situ RNA hybridization (Porteus et al., 1991, 1992; Bulfone et al., 1993a, 1993b). In this article we describe an antiserum against DLX-2 that we use to characterize its expression further. These studies are the first use of immu- 

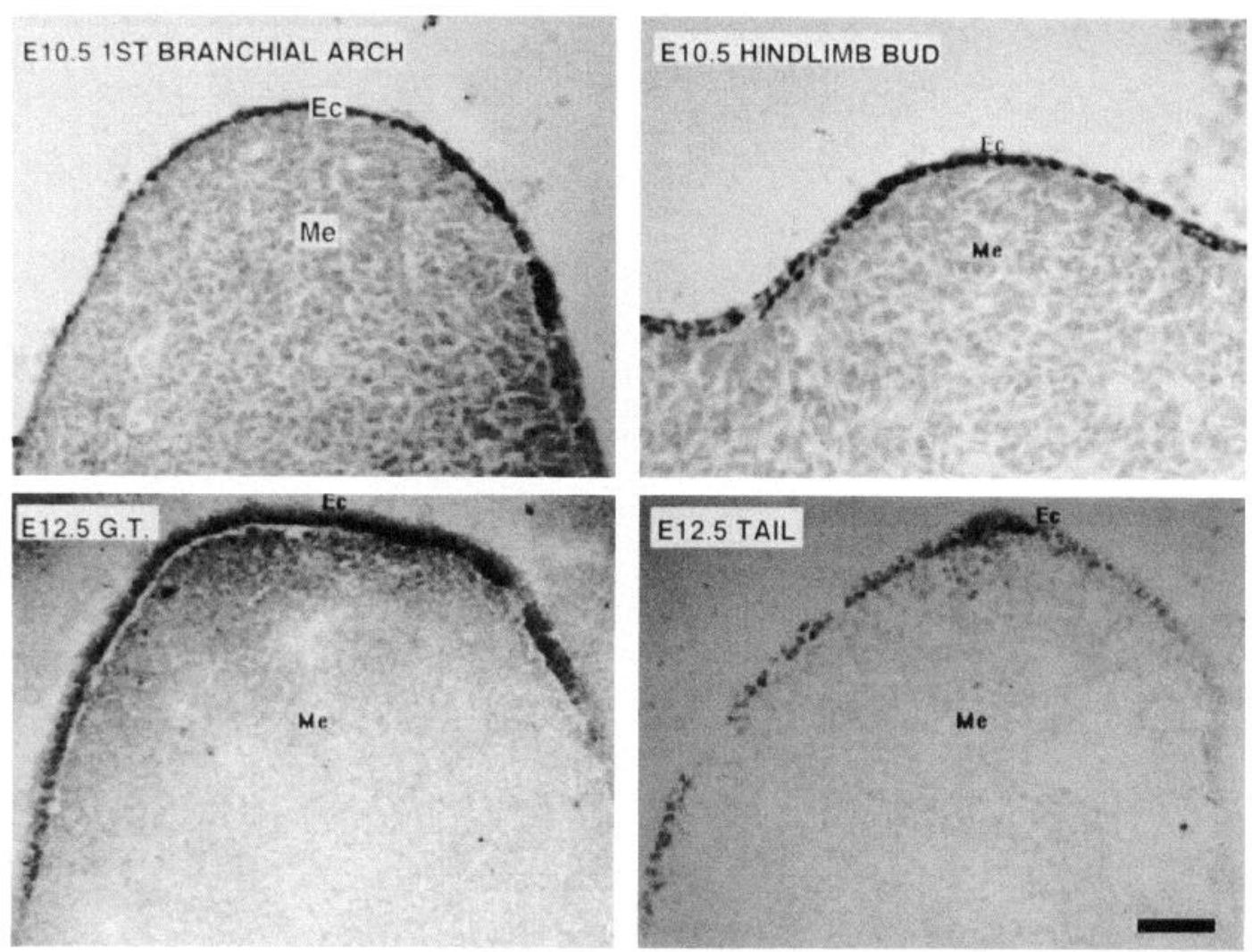

Figure 6. DLX-2 is expressed in the distal ectodermal cells of multiple structures of the mouse embryo. This figure shows DLX-2 expression by immunohistochemistry in mouse parasagittal sections from E10.5 branchial arch 1, E10.5 hindlimb bud, E12.5 genital tubercle (G.T.), and E12.5 tail. The most strongly labeled cells are in the ectodermal layer $(E c)$, with little or no labeling of the mesenchymal core $(M e)$. Scale bar: $80 \mu \mathrm{m}$ for the top left panel, $70 \mu \mathrm{m}$ for the top right panel, and $100 \mu \mathrm{m}$ for the bottom two panels.

nohistochemistry to characterize homeodomain protein expression in the mammalian embryonic forebrain, which greatly improved the sensitivity and resolution of our analysis and, consequently, revealed four new results: (1) DLX-2 is expressed in the distal ectoderm of structures that bud from the embryo; (2) DLX-2 expression persists in two domains in the embryonic forebrain, but expression in domain II expands into the olfactory bulb and cerebral cortex at later stages; (3) DLX-2 is expressed in periventricular cells in a stream from the ganglionic eminence to olfactory bulb in the embryo, newborn, and adult; (4) BrdU incorporation into S-phase cells, and the expression of DLX-2, MASH-1, and MAP-2 identify molecularly distinct populations of cells within the wall of the basal telencephalon and provide a basis for a model of stages of cellular differentiation.

\section{DLX-2 expression in the distal ectoderm of appendages and other structures}

Previously we reported that $D l x-2$ and $D l l$ are expressed in analogous structures of the mouse and fly: the embryonic brain, limbs, and face (Bulfone et al., 1993b). Mutations of the distalless gene in Drosophila disrupt development along the proximaldistal axis of limbs (Cohen and Jurgens, 1989; Cohen et al., 1989; Cohen, 1990; Vachon et al., 1992). Here we show that DLX-2 is expressed in the distal ectodermal cells of outgrowths from the embryo: the branchial arches, limb buds, frontonasal prominence, tail, and genital tubercle. The distal expression of
DLX-2 suggests that $D l x-2$, like its fly homolog distal-less, may play a role in establishing the proximal-distal axis in these developing structures.

Molecular studies of limb development have implicated a variety of growth factors and homeobox genes in the regulation of patterning and differentiation (Tabin, 1991; Izpisua-Belmonte and Duboule, 1992; Song et al., 1992; Niswander and Martin, 1993; Zakany and Duboule, 1993). For example, ectopic expression in the embryonic limb of Hox-D genes, which normally are expressed in overlapping patterns in the limb mesenchyme, cause predictable limb malformations (Morgan et al., 1992). $D l x-2$, as well as $D l x-1$ (Dolle et al., 1992), is expressed in the distal ectodermal portion of the limb bud. Similar to the developing limb bud, in the genital tubercle $D l x-2$ is expressed in the ectodermal cells surrounding a mesenchyme that has a graded pattern of expression of genes from the Hox-D locus (Dolle et al., 1991). Moreover, $D l x-2$ is linked to the Hox-D cluster on mouse and human chromosome 2 (McGuinness et al., 1992; Ozcelik et al., 1992). The structural and conserved expression relationship suggests that there may be a common gene cassette, similar in concept to that discussed by Jan and Jan (1993), involving the $D l x$ and $H o x-D$ genes. This gene cassette may be a common developmental program involving a particular set of genes used in multiple structures to accomplish a specific purpose. For $D l x-2$ and $H o x-D$, that purpose may be to regulate differentiation and morphogenesis in outgrowths from the embryo such as the limbs and genital tubercle. 

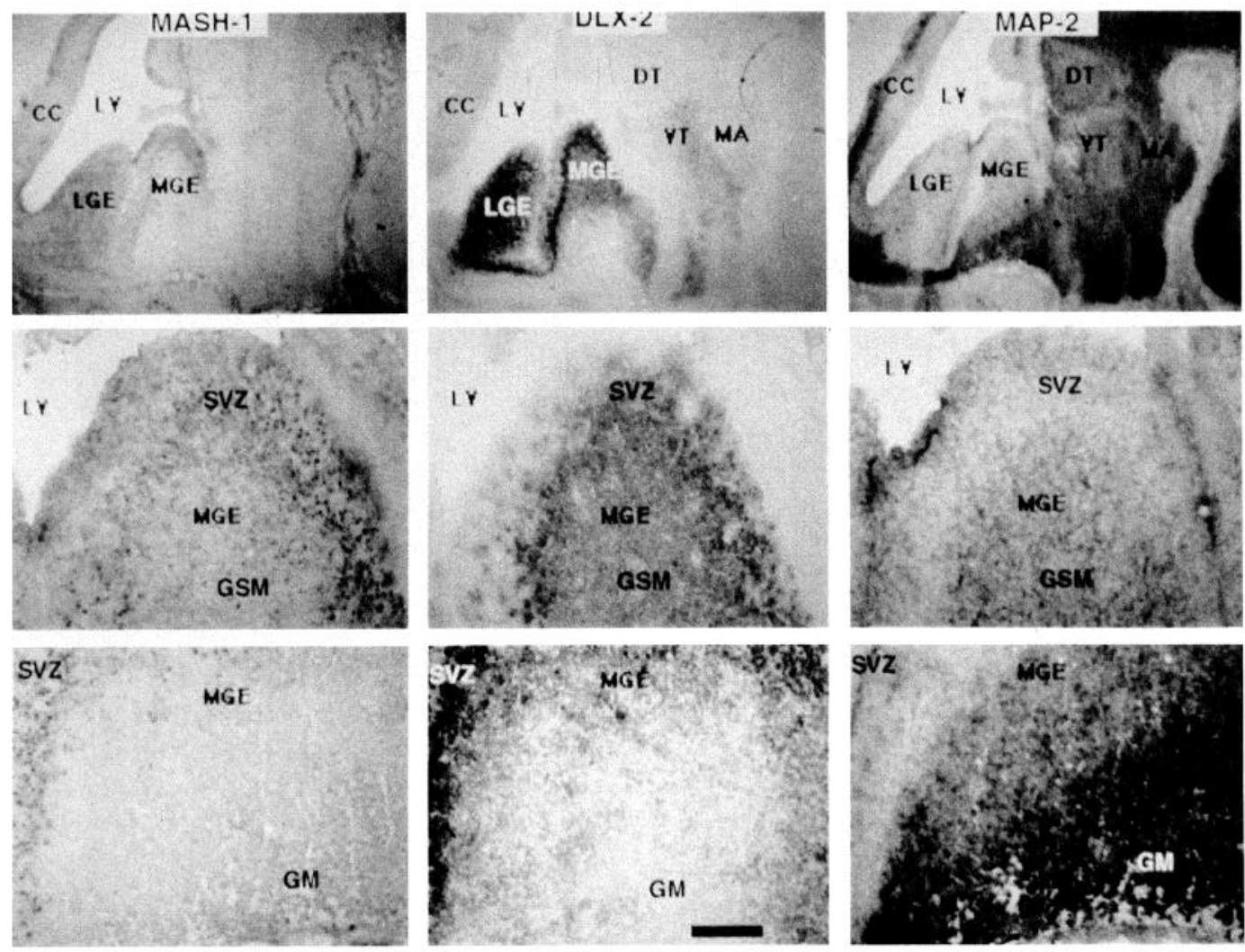

Figure 7. Comparison of DLX-2, MASH-1 and MAP-2 expression in the forebrain. This figure shows MASH-1, DLX-2, and MAP-2 expression by immunohistochemistry in adjacent parasagittal sections from a mouse E12.5 embryo. The left panels show MASH-1 expression, the middle panels show DLX-2 expression, and the right panels show MAP-2 expression. The bottom two rows are higher-magnification views of the same section shown in the top row. The subventricular zone (SVZ) shows strong MASH-1 and DLX-2 labeling but no MAP-2 labeling. The ganglionic mantle $(G M)$, conversely, shows no DLX-2 and MASH-1 labeling but strong MAP-2 labeling. In the ganglionic submantle (GSM), cells are labeled with intermediate levels of both DLX-2 and MAP-2. In the top row, similar intermediate levels of DLX-2 and MAP-2 staining can also be seen in the ventral thalamus, the preoptic area, and the suprachiasmatic nucleus. Scale bar: $350 \mu \mathrm{m}$ for the top row, $140 \mu \mathrm{m}$ for the bottom two rows.

\section{$D L X-2$ expression in the embryonic basal telencephalon extends into the cerebral cortex and the olfactory bulb}

Prior descriptions of $D l x-2$ expression have emphasized that there are several sharp boundaries of expression, as exemplified at the zona limitans, the border between the ventral thalamus and dorsal thalamus (Porteus et al., 1991; Bulfone et al., 1993 a,b). Consistent with these results, we found no evidence of DLX-2 expression in the dorsal thalamus (Figs. 2,3). Thus, the zona limitans is an example of one of the distinct borders of DLX-2 expression that is present throughout development. In contrast, early in development (E9.5-E12.5) there is a border of DLX-2 expression between the lateral ganglionic eminence on one side, and the cerebral cortex and the primordia of the olfactory bulb on the other. By E16.5, however, DLX-2 expression extends into the olfactory bulb and cerebral cortex (Fig. 2). Thus, there are extensions of DLX-2 expression domains later in development.

One of the distinguishing features of DLX-2 expression late in gestation is the stream of DLX-2-positive cells that spans the periventricular region of the rostralmost part of the ganglionic eminence/basal ganglia to the olfactory bulb. This stream of DLX-2-positive cells is present from E16.5 to the adult. $D l x-1$ may be expressed along the same stream of cells (Salinas and Nusse, 1992). In our studies it is difficult to distinguish between the possibility of de novo expression in cells of the olfactory bulb or an origin from DLX-2-expressing cells in the lateral ganglionic eminence and a subsequent migration into the olfactory bulb.

There are two sets of studies that give circumstantial evidence that DLX-2-expressing cells migrate into the olfactory bulb. The first line of studies demonstrate a migratory pathway between from the anterior subventricular zone of the lateral ventricle to the olfactory bulb (Hinds, 1968; Altman, 1969; Bayer, 1983; Luskin, 1993). Luskin (1993) used retroviral labeling experiments to demonstrate a migratory pathway from the anterior subventricular zone, an area bordered by the cerebral cortex and lateral ganglionic eminence, into the olfactory bulb. The pathway of migration into the olfactory bulb corresponds to the position where DLX-2 is expressed late in development and in the adult mouse.

The second line of studies is the migration of luteinizing hormone-releasing hormone (LH-RH)-producing cells. These cells are born in the olfactory placode and then migrate into the brain through the olfactory bulb to their final destination in the hypothalamus (Schwanzel-Fukuda and Pfaff, 1989, 1990; Wray et al., 1989). DLX-2 is expressed in the olfactory placode, olfactory bulb, and hypothalamus and thus labels much of this migratory pathway. It may be that cells migrating along this pathway express DLX-2. This pathway of LH-RH cell migration is in the opposite direction than the migration from the anterior subventricular zone to the olfactory bulb described above. Thus, 

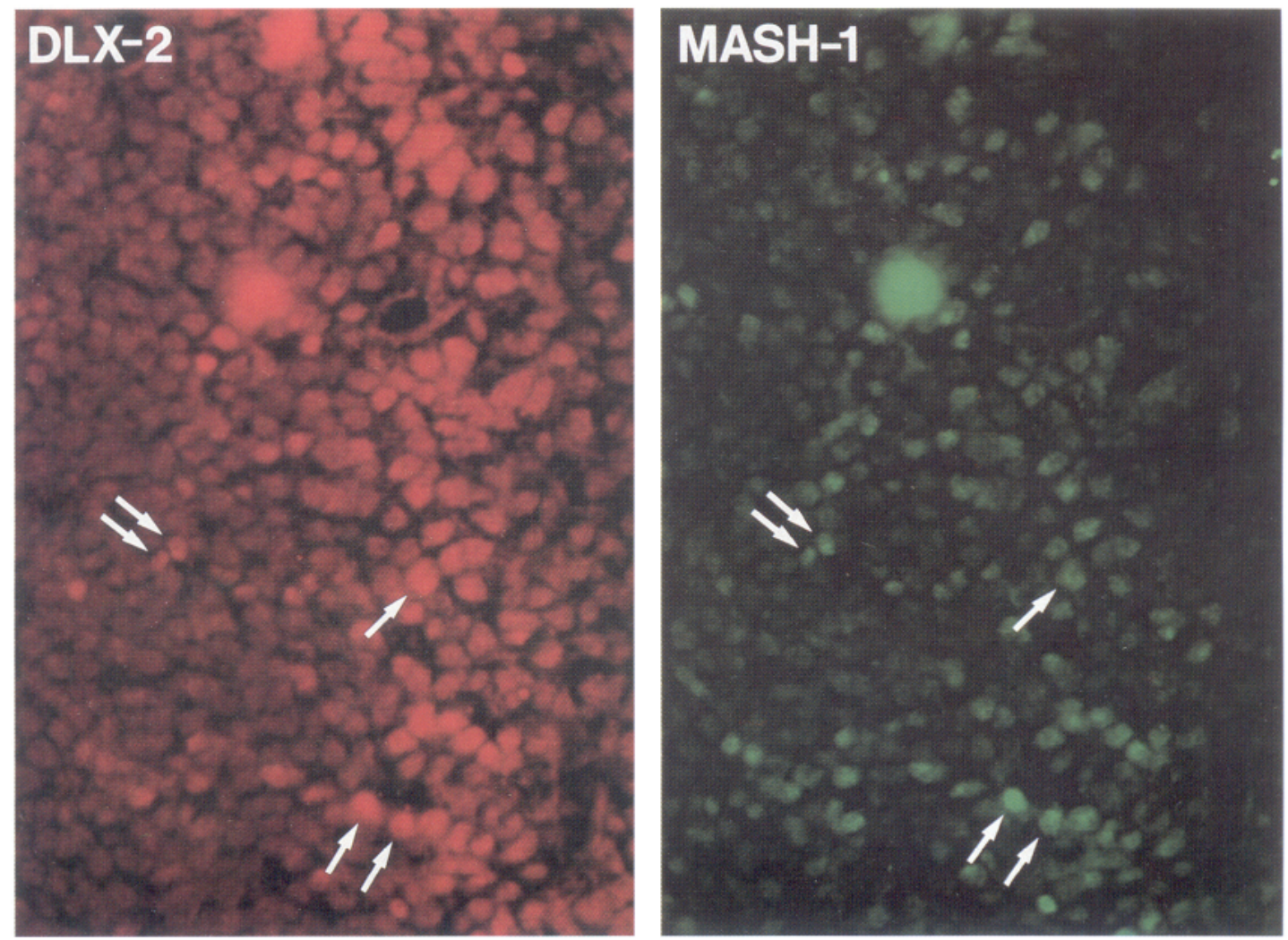

Figure 8. Coexpression of MASH-1 and DLX-2 in cells of the ganglionic eminence. This figure shows MASH-1 and DLX-2 expression by indirect immunofluorescence in a parasagittal section of a mouse E12.5 ganglionic eminence. The left panel shows DLX-2 expression using a rhodamineconjugated secondary antibody. The right panel shows MASH-1 expression using a fluorescein-conjugated secondary antibody. The arrows identify examples of cells that are both DLX-2 and MASH-1 positive.

there are bidirectional migrations in DLX-2-expressing domains of the basal telencephalon, suggesting that DLX-2-expressing cells may migrate.

In addition, DLX-2-expressing cells are present in the cerebral cortex. These DLX-2-expressing cells are sparsely dispersed in various layers. Cortical DLX-2-positive cells are seen next to the lateral ganglionic eminence, but are lacking near the septum, which also expresses DLX-2. These cells may be born in the cerebral cortex or arise by migration from the ganglionic eminence. Fishell et al. (1993) have evidence for a barrier to migration between these two zones because DiI-labeled ventricular zone cortical cells, which do not express DLX-2, do not readily migrate into the ganglionic eminence. On the other hand, migration between these two zones may occur at layers other than the ventricular zone, in particular, the subventricular, intermediate, or mantle zones. Recently, O'Rourke et al. (1992) have observed tangential cell movement within the subventricular and intermediate zones of the cerebral cortex. Furthermore, Walsh and Cepko (1993) have shown that there is widespread clonal dispersion in the cerebral cortex, emphasizing the existence of tangential migrations within the cortex. Finally, Halliday and Cepko (1992) have stated that within the subventricular zone of the ganglionic eminence there is tangential movement. Since essentially all subventricular zone cells of the medial and lateral ganglionic eminence express DLX-2, Halliday and Cepko's studies suggest that DLX-2-expressing cells are capable of tangential movement. Further studies will establish whether there are cell migrations within the subventricular, intermediate, or mantle zones from the ganglionic eminence or olfactory bulb to the neocortex.

\section{$D L X-2$ expression in the adult brain}

In the adult brain there is a set of DLX-2-expressing cells along the surface of the striatum, under the corpus callosum, that extend into the olfactory bulb. The adult DLX-2-expressing cells lie in a region that corresponds to a proliferative zone in the embryo. Morphologically, the DLX-2-expressing cells are small with a large nuclear to cytoplasmic ratio similar to the DLX-2-expressing cells in the embryo. Thus, the adult DLX2-expressing cells share similar characteristics to the immature embryonic DLX-2-expressing cells. Recently, neuronal stem cell lines have been established from the adult brain using different mixtures of purified growth factors (Ronnett et al., 1990; Reynolds and Weiss, 1992; Richards et al., 1992). These studies suggest that either these growth factors can induce dedifferentiation of mature neurons or that there is a population of undifferentiated cells in the adult brain that can give rise to neurons. The newly developed cell lines, therefore, may have been derived from DLX-2-expressing or similarly less differentiated cells present in the adult brain.

A separate issue is what the cell types are in the adult brain that arise from DLX-2-expressing cells. There are two pieces of evidence that some DLX-2-expressing cells are part of the neuronal lineage. The first is that DLX-2 is coexpressed with MAP-2, a marker of terminal neuronal differentiation. The second is that DLX-2 is expressed in essentially every cell of the 

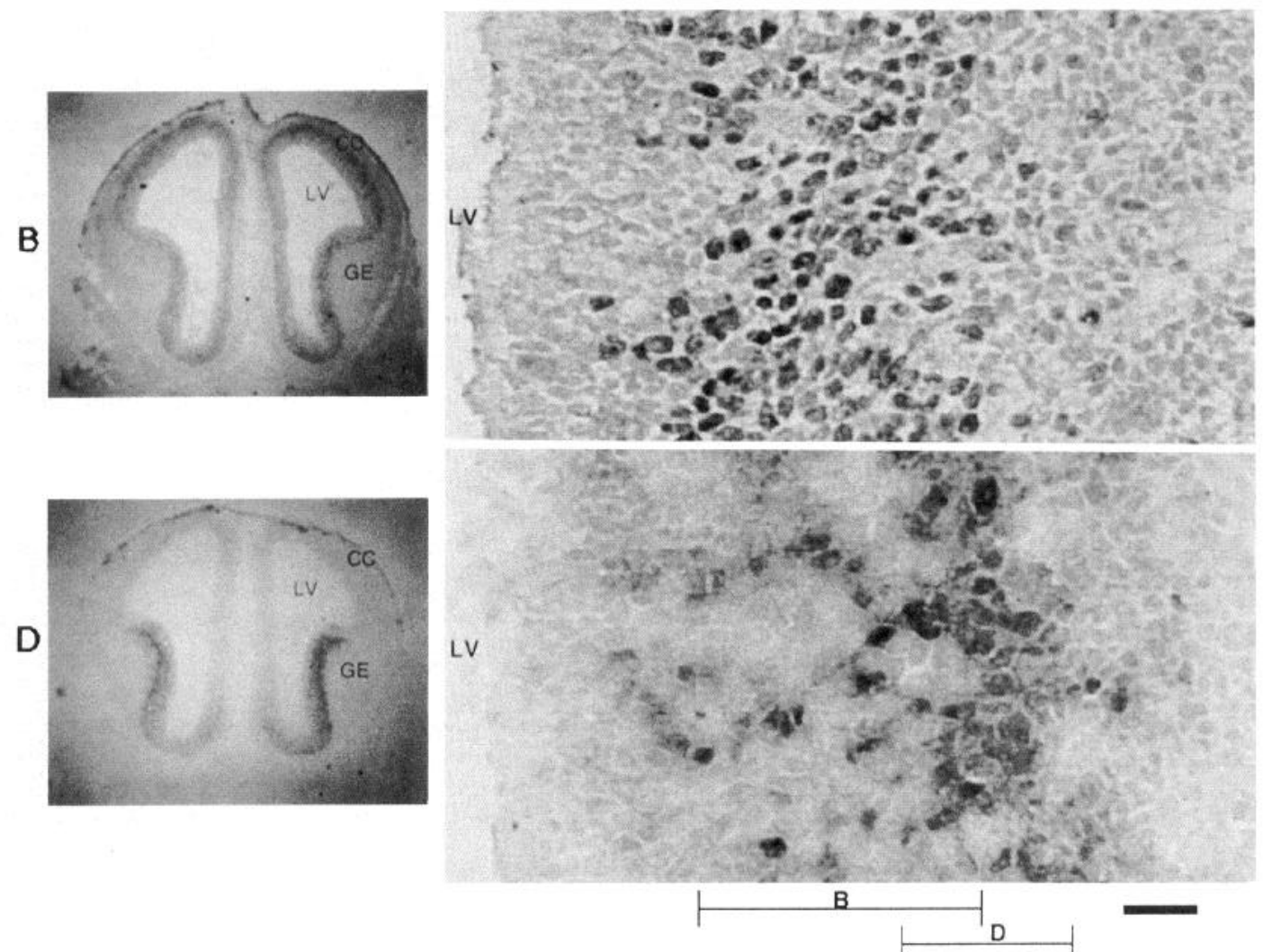

Figure 9. Comparison of DLX-2 expression with S-phase of the cell cycle. This figure shows DLX-2 expression and bromodeoxyuridine (BrdU) incorporation in adjacent coronal sections from an E12.5 mouse that had been injected with BrdU $1 \mathrm{hr}$ before sacrifice. The top row, labeled $B$, shows BrdU incorporation, and the bottom row, labeled $D$, shows DLX-2 expression. The right column is a higher magnification of a region of the medial ganglionic eminence from the left column. In the right column, the lateral ventricle $(L V)$ is labeled. At the bottom the span of dense BrdU incorporation (labeled $B$ and dense DLX-2 expression (labeled $D$ ) is marked. In summary, this figure demonstrates that cells that express DLX-2 overlap with cells that are still undergoing S-phase of the cell cycle. Scale bar: $400 \mu \mathrm{m}$ for the left panels, $25 \mu \mathrm{m}$ for the right panels.

subventricular zone and ganglionic submantle during a period of active neurogenesis and limited gliogenesis.

Late in gestation and postnatally, DLX-2 is expressed in the subventricular zone of the cerebral cortex and striatum. Several studies have suggested that the fate of postnatal subventricular zone cells is to become oligodendrocytes (Altman, 1966; Imamoto et al., 1978; Levine and Goldman, 1988a,b; Hardy and Reynolds, 1991; Levison and Goldman, 1993). Recently, Levison and Goldman (1993) have demonstrated that both oligodendrocytes and astrocytes develop from progenitors in the rat postnatal subventricular zone. Therefore, it is likely that DLX2-expressing cells in the postnatal subventricular zone give rise to glia. Conclusive evidence for DLX-2 expression in the glial lineage will come either by staining purified populations of cells that are known to be part of the glial lineage or by double labeling with glial-specific markers. Nonetheless, DLX-2 is probably expressed in both neuronal and glial lineages.

\section{Molecularly distinct populations in the developing ganglionic eminence}

During development, cells pass through various stages of differentiation, a process that may or may not be accompanied by overt morphologic change. Implicit is that the changes involved in differentiation are molecular and are reflected in the composite of gene expression at a given stage. Previously, the state of differentiation of a cell in the forebrain has been deduced from its spatial location along the ventricular-pial or radial axis and its morphology. Thus, cells in the ventricular zone are more undifferentiated than those in the subventricular zone, which are more undifferentiated than those in the mantle zone. But, as in hematopoiesis, differentiation may occur without change in spatial location and be unrecognized using a spatial and/or morphologic classification. Similarly, cells of different lineages can not be distinguished based on their spatial location during development. That is, as in the hematopoietic system, cells of different lineages may be neighbors. Molecular markers can be used to resolve different lineages or stages of differentiation. In this study we believe we use markers of different stages of differentiation rather than of different lineages for two reasons. First, these markers are expressed in essentially $100 \%$ of the cells of particular regions. For example, DLX-2 is expressed in essentially all cells of the subventricular zone and ganglionic submantle, and MAP-2 is expressed in essentially all cells of the mantle zone at E12.5. It is possible that a given region contains only a single lineage, but we believe it is more likely that the markers are lineage nonspecific. Second, MAP-2, MASH1 , and the incorporation of $\mathrm{BrdU}$ are known to be lineagenonspecific markers (Garner et al., 1988; Guillemot et al., 1993).

Based on our analysis of the expression patterns of DLX-2, MASH-1, and MAP-2 and the incorporation of BrdU into S-phase of mitotic cells, we can define four molecularly distinct populations of cells within the ganglionic eminence (Table 2). 


\begin{tabular}{llllll}
\hline Table & 2. & Molecular characteristics of four different cell populations \\
$\begin{array}{l}\text { Popu- } \\
\text { lation }\end{array}$ & Location & BRDU & DLX-2 & MASH-1 & MAP-2 \\
\hline I & VZ & $+++/-$ & - & - & - \\
II & VZ/SVZ & $+++/-$ & +++ & +++ & - \\
III & SVZ/GSM & - & ++ & ++ & ++ \\
IV & GM & - & - & - & +++
\end{tabular}

This table identifies the molecular characteristics of four populations of cells in the ganglionic eminence identified in this study. "POP"-Population number; "LOC"-location within the ganglionic eminence; "BRDU"- intensity of BrdU staining; "DLX-2"-intensity of DLX-2 staining; "MASH-1"-intensity of mash-1 staining; "MAP-2"-intensity of MAP-2 staining.

Population I cells reside in the ventricular zone, are actively mitotic, and do not express DLX-2 or MASH-1. Within population I cells are either labeled or unlabeled by BrdU, depending on what part of the cell cycle they are in. The strong band of BrdU labeling in the ventricular zone reflects the known pattern of interkinetic nuclear migration of mitotically active ventricular zone cells (Takahashi et al., 1993). This population contains cells that are the early progenitors of the developing ganglionic eminence.

Population II cells express DLX-2 and MASH-1 but do not express MAP-2. As in population I, population II cells will show a heterogeneity in BrdU labeling, depending on when in the cell cycle they are examined. The majority of population II cells reside in the subventricular zone but an important fraction are found in the ventricular zone. Population II ventricular zone cells can be seen as radially aligned columns of cells in Figure 9. We hypothesize that population II cells in the ventricular zone are in the process of moving into the subventricular zone. The existence of population I and II cells in the ventricular zone highlights the possibility of heterogeneity of cell types and/or stages within a given region. Further, population II cells highlight the possibility that cells in different regions may be molecularly identical.

Studies by McConnell and Kaznowski (1991) emphasize the importance of the milieu in which a cell undergoes its final S-phase as an important determinant for the cell's final laminar location in the developing cerebral cortex. While we have not demonstrated that cells do not undergo mitosis after passing through population II, it is plausible that population II may be stages when master regulatory genes, such as Mash-1 and $D l x$ 2 , imprint their effects on cells undergoing their final mitosis and complete the process of differentiation.

Population III cells express DLX-2, MASH-1 and MAP-2 at intermediate levels and do not incorporate BrdU. Population III cells primarily reside in the ganglionic submantle, a layer between the subventricular and mantle zones. There may also be some population III cells in the subventricular zone that are beginning to migrate into the ganglionic submantle. We hypothesize that cells in population III are in the midst of a transition from relatively undifferentiated stages, characterized by high levels of DLX-2 and MASH-1 expression, to stages of terminal differentiation, characterized by high levels of MAP-2 expression.

Finally, population IV cells express high levels of MAP-2 but do not express DLX-2 or MASH-1, or incorporate BrdU. Population IV cells reside in the ganglionic mantle. At E12.5, population IV cells also express the $G b x$ - 2 homeobox genes (Bulfone et al., 1993a).
In summary, we propose that the four populations correspond to four different stages of differentiation in the ganglionic eminence. Generally the four stages of differentiation have distinct positions along the ventricular-pial axis, but populations I and II highlight the possibility that differentiation may occur without change in location. We imagine, in fact, that cells undcrgo more than three transitions and, within any given spatial location, may undergo multiple molecular transitions. We hope that this model provides the beginning of a framework for understanding the different stages of neuronal differentiation in the mammalian forebrain. This framework should help in the interpretation of experiments that study the effect of altering the function or cxpression of genes that regulate forebrain development.

\section{References}

Altman J (1966) Proliferation and migration of undifferentiated precursor cells in the rat during postnatal gliogenesis. Exp Neurol 16 : 263-278.

Altman J (1969) Autoradiographic and histological studies of postnatal neurogenesis. IV. Cell proliferation and migration in the anterior forebrain, with special reference to persisting neurogenesis in the olfactory bulb. J Comp Neurol 137:433-457.

Bayer SA (1983) ${ }^{3} \mathrm{H}$-thymidine-radiographic studies of neurogenesis in the rat olfactory bulb. Exp Brain Res 50:329-340.

Beauchemin M, Savard P (1992) Two distal-less related homeoboxcontaining genes expressed in regeneration blastemas of the newt. Dev Biol 154:55-65.

Bulfone A, Puelles L, Porteus MH, Frohman MA, Martin GR, Rubenstein JLR (1993a) Spatially restricted expression of $D l x-1, D l x-2$ (Tes-l), Gbx-2 and $W n t-3$ in the embryonic day 12.5 mouse forebrain defines potential transverse and longitudinal segmental boundaries. J Neurosei 13:3155-3172.

Bulfone A, Kim HJ, Puelles L, Porteus MH, Grippo J, Rubenstein JLR (1993b) The mouse $D l x-2(T e s-1)$ gene is expressed in spatially restricted domains of the forebrain, face and limbs in midgestation of mouse embryos. Mech Dev 40:129-140.

Cohen SM (1990) Specification of limb development in the Drosophila embryo by positional cues from segmentation genes. Nature 343:173177.

Cohen SM, Jurgens G (1989) Proximal-distal pattern formation in Drosophila: cell autonomous requirements for distal-less gene activity in limb development. EMBO J 8:2045-2055.

Cohen SM, Bronner G, Kuttner F, Jurgens G, Jackle H (1989) Distalless encodes a homeodomain protein required for limb development in Drosophila. Nature 338:432-434.

Dolle P, Izpisua-Belmonte J-C, Brown JM, Tickle C, Duboule D (1991) $H o x-4$ genes and the morphogenesis of mammalian genitalia. Genes Dev 5:1767-1776.

Dolle P, Price M, Duboule, D (1992) Expression of the murine $D l x-1$ homeobox gene during facial, ocular and limb development. Differentiation 49:93-99.

Ekker M, Akimenko MA, Bremiller R, Westerfield M (1992) Regional expression of three homeobox transcripts in the inner ear of zebrafish embryos. Neuron 9:27-35.

Figdor MC, Stern CD (1993) Segmental organization of the embryonic diencephalon. Nature 363:630-634.

Fishell G, Mason CA, Hatten ME (1993) Dispersion of neural progenitors within the germinal zones of the forebrain. Nature 362:636638.

Fraser S, Keynes R, Lumsden A (1990) Segmentation in the chick embryo hindbrain is defined by cell lineage restrictions. Nature 344 : $431-435$.

Garner CG, Brugg B, Matus A (1988) A 70-kilodalton microtubuleassociated protein (MAP2c), related to MAP2. J Neurochem 50:609615.

Guillemot F, Joyner AL (1993) Dynamic expression of the murine achaete-scute homolog (MASH-1) in the developing nervous system. Mech Dev 42:171-185.

Guillemot F, Lo L-C, Johnson JE, Auerbach A, Anderson DJ, Joyner AL (1993) Mammalian achaete-scute homolog 1 is required for the early development of olfactory and autonomic neurons. Cell 75:463 476. 
Halliday AL, Cepko CL (1992) Generation and migration of cells in the developing striatum. Neuron 9:15-26.

Hardy R, Reynolds R (1991) Proliferation and differentiation potential of rat forebrain oligodendrocyte progenitors both in vitro and in vivo. Development 111:1061-1080.

Hinds JW (1968) Autoradiographic study of histogenesis in the mouse olfactory bulb. II. Cell proliferation and migration. J Comp Neurol 134:305-322.

Imamoto K, Paterson JA, Leblond CP (1978) Radioautographic investigation of gliogenesis in the corpus callosum of young rats. I. Sequential changes in oligodendrocytes. J Comp Neurol 180:115138

Izpisua-Belmonte J-C, Duboule D (1992) Homeobox genes and pattern formation in the vertebrate limb. Dev Biol 152:26-36.

Jan YN, Jan LY (1993) Functional gene cassettes in development. Proc Natl Acad Sci USA 90:8305-8307.

Keynes R, Lumsden A (1990) Segmentation and the origin of regional diversity in the vertebrate central nervous system. Neuron 2:1-9.

Krumlauf R, Marshall H, Studer M, Nonchev S, Sham MH, Lumsden A (1993) Hox homeobox genes and regionalization of the nervous system. J Neurobiol 24:1328-1340.

Lawrence PA (1992) The making of a fly: the genetics of animal design. London: Blackwell.

LeVine SM, Goldman JE (1988a) Embryonic divergence of oligodendrocyte and astrocyte lineages in developing rat cerebellum. J Neurosci 8:3992-4006.

LeVine SM, Goldman JE (1988b) Spatial and temporal patterns of oligodendrocyte differentiation in rat cerebrum and cerebellum. $\mathrm{J}$ Comp Neurol 277:441-455.

Levison SW, Goldman JE (1993) Both oligodendrocytes and astrocytes develop from progenitors in the subventricular zone of postnatal rat forebrain. Neuron 10:201-212.

Lo L-C, Johnson JE, Wuenschell CW, Saito T, Anderson DJ (1991) Mammalian achaete-scute homolog 1 is transiently expressed by spatially restricted subsets of early neuroepithelial and neural crest cells. Genes Dev 5:1524-1537.

Lumsden A, Keynes R (1989) Segmental patterns of neuronal development in the chick hindbrain. Naturc 33:424-428.

Luskin MB (1993) Restricted proliferation and migration of postnatally generated neurons derived from the forebrain subventricular zone. Neuron 11:173-189.

McConnell SK, Kaznowski CE (1991) Cell cycle dependence of laminar determination in developing neocortex. Science 254:282-285.

McGinnis W, Krumlauf R (1992) Homeobox genes and axial patterning. Cell 68:283-302.

McGuinness TL, MacDonald G, Koch TK, Rubenstein JLR (1992) Evidence for linkage of Tes- 1 and $D l x-1$, two homeobox genes expressed in the developing mammalian forebrain. Soc Neurosci Abstr 18:404.5.

Morgan BA, Izpisua-Belmonte J-C, Duboule D, Tabin CJ (1992) Targeted misexpression of $H o x-4.6$ in the avian limb bud causes apparent homeotic transformations. Naturc 358:236-239.

Niswander L, Martin GR (1993) FGF-4 and BMP-2 have opposite effects on limb growth. Nature 361:68-71.

O'Rourke NA, Dailey ME, Smith SJ, McConnell SK (1992) Diverse migratory pathways in the developing cerebral cortex. Science 258 : 299-302.

Ozcelik T, Porteus MH, Rubenstein JLR, Francke U (1992) DLX2 (TES1), a homeobox gene of the Distal-less family, assigned to conserved regions on human and mouse chromosomes 2. Genomics 13: 1157-1161.

Papalopulu N, Kintner C (1993) Xenopus distal-less related homeobox genes are expressed in the developing forebrain and are induced by planar signals. Development 117:961-975.
Porteus MH, Bulfone A, Ciaranello RD, Rubenstein JLR (1991) Isolation and characterization of a novel cDNA clone encoding a homeodomain that is developmentally regulated in the ventral forebrain. Neuron 7:221-229.

Porteus MH, Brice AEJ, Bulfone A, Usdin TB, Ciaranello RD, Rubenstein JLR (1992) Isolation and characterization of a library of cDNA clones that are preferentially expressed in the embryonic telencephalon. Mol Brain Res 12:7-22.

Price M, Lemaistre M, Pischetola M, DiLauro R, Duboule D (1991) A mouse gene related to Distal-less shows a restricted expression in the developing forebrain. Nature 351:748-751.

Puelles L, Rubenstein JLR (1993) Expression patterns of homeobox and other putative regulatory genes in the embryonic mouse forebrain suggest a neuromeric organization. Trends Neurosci 16:472-479.

Reynolds BA, Weiss S (1992) Generation of neurons and astrocytes from isolated cells of the adult mammalian central nervous system. Science 255:1707-1710.

Richards LJ, Kilpatrick TJ, Bartlett PF (1992) De novo generation of neuronal cells from the adult mouse brain. Proc Natl Acad Sci USA 89:8591-8585.

Robinson GW, Wray S, Mahon KA (1991) Spatially restricted expression of a member of a new family of murine Distal-less homeobox genes in the developing forebrain. New Biol 3:1183-1194.

Ronnett GV, Hester LD, Nye JS, Connors K, Snyder SH (1990) $\mathrm{Hu}-$ man cortical neuronal cell line: establishment from a patient with unilateral megalencephaly. Science 248:603-605.

Rubenstein JLR, Puelles L (in press) Homeobox gene expression during development of the vertebrate brain. In: Current topics in developmental biology (Pederson R, ed), in press. New York: Academic.

Salinas PC, Nusse R (1992) Regional expression of the Wnt-3 gene in developing mouse forebrain in relationship to diencephalic neuromeres. Mech Dev 39:151-160.

Sambrook J, Fritsch EF, Maniatis T (1989) Molecular cloning: a laboratory manual. Cold Spring Harbor, NY: Cold Spring Harbor Laboratory.

Schwanzel-Fukuda M, PfaffDW (1989) Origin of luteinizing hormonereleasing hormone neurons. Nature 338:161-164.

Schwanzel-Fukuda M, Pfaff DW (1990) The migration of luteinizing hormone-releasing hormone (LH-RH) neurons from the medial olfactory placode into the medial basal forebrain. Experientia 46:956961.

Song K, Wang Y, Sassoon D (1992) Expression of Hox-7.1 in myoblasts inhibits terminal differentiation and induces cell transformation. Nature 360:477-481.

Tabin CJ (1991) Retinoid, homeoboxes and growth factors: towards molecular models for limb development. Cell 66:199-217.

Takahashí T, Nowakowski RS, Caviness VS Jr (1993) Cell cycle parameters and patterns of nuclear movement in the neocortical proliferative zone of the fetal mouse. J Neurosci 13:820-828.

Vachon G, Cohen B, Pfeifle C, McGuffin ME, Botas J, Cohen SM (1992) Homeotic genes of the bithorax complex repress limb development in the abdomen of the Drosophila embryo through the target gene Distal-less. Cell 71:437-450.

Walsh C, Cepko CL (1993) Clonal dispersion in proliferative layers of developing cerebral cortex. Nature 362:632-635.

Wray S, Grant P, Gainer H (1989) Evidence that cells expressing luteinizing hormone-releasing hormone mRNA in the mouse are derived from progenitor cells in the olfactory placode. Proc Natl Acad Sci USA 86:8132-8136.

Zakany J, Duboule D (1993) Correlation of expression of Wnt-I in developing limbs with abnormalities in growth and skeletal patterning. Nature 362:546-549. 